\title{
Cobalt, manganese, and iron near the Hawaiian Islands: A potential concentrating mechanism for cobalt within a cyclonic eddy and implications for the hybrid-type trace metals
}

\author{
Abigail E. Noble ${ }^{a, b,+}$ and Mak A. Saito, ${ }^{a,+, *}$ \\ Kanchan Maiti ${ }^{\mathrm{c}}$, Claudia Benitez-Nelson ${ }^{\mathrm{c}}$ \\ ${ }^{a}$ Marine Chemistry and Geochemistry Department \\ Woods Hole Oceanographic Institution \\ 266 Woods Hole Rd. MS\#51 \\ Woods Hole MA 02543 \\ ${ }^{\text {b } M I T-W H O I ~ J o i n t ~ P r o g r a m ~ i n ~ C h e m i c a l ~ O c e a n o g r a p h y ~}$ \\ Massachusetts Institute of Technology \\ 77 Massachusetts Ave. \\ Cambridge, MA 02139 \\ cDepartment of Geological Sciences \\ University of South Carolina \\ Columbia SC 29208 \\ ${ }^{+}$Co-authors \\ *Corresponding author: mak@whoi.edu
}

Fax: 508-457-2193

Revised for Deep-Sea Research II

9.26.07 


\begin{abstract}
The vertical distributions of cobalt, iron, and manganese in the water column were studied during the E-Flux Program (E-Flux II and III), which focused on the biogeochemistry of cold-core cyclonic eddies that form in the lee of the Hawaiian Islands. During E-Flux II (January 2005) and E-Flux III (March 2005), 17 stations were sampled for cobalt $(\mathrm{n}=147)$, all of which demonstrated nutrient-like depletion in surface waters. During E-Flux III, two depth profiles collected from within a mesoscale coldcore eddy, Cyclone Opal, revealed small distinct maxima in cobalt at $\sim 100 \mathrm{~m}$ depth and a larger inventory of cobalt within the eddy. We hypothesize that this was due to a cobalt concentrating effect within the eddy, where upwelled cobalt was subsequently associated with sinking particulate organic carbon (POC) via biological activity and was released at a depth coincident with nearly complete POC remineralization (Benitez-Nelson et al. 2007). There is also evidence for the formation of a correlation between cobalt and soluble reactive phosphorus during E-Flux III relative to the E-Flux II cruise that we suggest is due to increased productivity, implying a minimum threshold of primary production below which cobalt-phosphate coupling does not occur. Dissolved iron was measured in E-Flux II and found in somewhat elevated concentrations $(\sim 0.5 \mathrm{nM})$ in surface waters relative to the iron depleted waters of the surrounding Pacific (Fitzwater et al. 1996), possibly due to island effects associated with the iron-rich volcanic soil from the Hawaiian Islands and/or anthropogenic inputs. Distinct depth maxima in total dissolved cobalt were observed at 400 to $600 \mathrm{~m}$ depth, suggestive of the release of metals from the shelf area of comparable depth that surrounds these islands.
\end{abstract}

Keywords: Hybrid-type metals, cobalt, iron, manganese, trace metal biogeochemistry, lee eddies. Regional Terms: Central North Pacific, Hawaiian Islands, lee of Hawaii 


\section{Introduction}

In recent years, the importance of bioactive trace elements for marine phytoplankton nutrition has become evident. In particular, iron is now believed to limit primary productivity in major regions of the oceans, and other bioactive trace elements are known to be important micronutrients (Martin et al. 1991, Sunda and Huntsman 1995, Saito et al. 2002, Morel et al. 2003 and references therein, Saito et al. 2004, Bruland et al. 2005). The processes that control the distributions of trace elements in seawater have been generally outlined in recent years (e.g. Edmond et al. 1979, Martin et al. 1991, Johnson et al. 1997, Gordon et al. 1998, Boyle et al. 2005), but much of the specific nature of what controls their distributions remains to be understood. In particular, the hybrid-type trace metals, which are simultaneously influenced by both micronutrient and scavenging processes, can show significant variability in seawater (Bruland and Lohan 2004, and references therein). There is much to be learned with regards to how these competing processes influence the distributions of hybrid-type metals like iron and cobalt, and how that in turn interacts with marine ecosystem processes.

\subsection{Potential Influences on Trace Metal Distributions Among the Hawaiian Islands:}

There are a number of potential controls on trace metal distribution in the marine water column, including: 1) aeolian deposition, 2) hydrothermal inputs, 3) riverine inputs, 4) exports to and imports from sediments, 5) horizontal advection, and 6) loss by export of metals associated with organic and mineral particles (Sedwick et al. 1992, Wong et al. 1995, DeCarlo et al. 2004, Saito et al. 2004, Boyle et al. 2005, Bruland et al. 2005, DeCarlo et al. 2005, Sedwick et al. 2005). Recent studies in the vicinity of the Hawaiian Islands have found evidence that all of these processes are influencing trace metal distributions. Temporal variability in surface iron at station ALOHA $\left(22^{\circ} 45^{\prime} \mathrm{N}\right.$, $\left.158^{\circ} 00^{\prime} \mathrm{W}\right)$, located north of the Hawaiian Islands in the Subtropical North Pacific Gyre, has been attributed to both aeolian input and biological uptake as well as hydrothermal activity from Loihi Seamount (Boyle et al. 2005). A study by Brown et al. (2005) revealed highly variable surface dissolved iron concentrations from a transect across the North Pacific Subtrobical Gyre that ended at station ALOHA. While surface concentrations near the Hawaiian Islands were notably higher than those at more open 
ocean stations within the gyre, deep concentrations were comparable, and variability was argued to be due to both aeolian deposition and fluvial input (Brown et al. 2005).

Hydrothermal studies in this area have demonstrated that seamounts and vents provide input of metals to deep waters. Dissolved ferrous iron concentrations reached almost $1 \mathrm{mmol} \mathrm{kg}^{-1}$ in the fluids of Pele's Vents, an area of the Loihi Seamount, and the plume from Loihi is believed to influence iron concentrations at depth at station ALOHA based on high $\delta^{3}$ He values indicative of a hydrothermal signal (Sedwick et al. 1992, Boyle et al. 2005). Four years after this vent study, a volcanic event destroyed the sampling area and gave way to several new venting sites. Later studies conducted in this area by a remote sampler observed similar high Fe concentrations (Wheat et al. 2000).

Rivers have been identified as a source of trace metals to Hawaiian watersheds and surrounding waters. Two studies, conducted by DeCarlo et al. (2004, 2005), examined concentrations of lead, zinc, copper, barium, cobalt, arsenic, nickel, vanadium, and chromium in streambeds on the island of Oahu. They found that most metals are supplied to the ocean via the particulate fraction during storm events, and that the dissolved fraction comprises only $1 \%$ of the total metal contribution (DeCarlo et al. 2004, DeCarlo et al. 2005). The dissolved fraction of metals showed a combination of sources including anthropogenic contributions from urban areas (vehicular traffic and industrial operations) and agriculture (fertilizers) (DeCarlo et al. 2004). Finally, direct input from shelf sediments around the islands is also a likely source of metals as the islands of Maui, Kahoolawe, Molokai, and Lana'i are surrounded by an expansive shelf ( $\sim 500 \mathrm{~m}$ depth, Figure 1b) comprised of mafic and felsic minerals (Chase et al. 1980).

\subsection{Influences on Cobalt, Manganese, and Iron Marine Biogeochemistry}

Although trace elements are now known to be essential components for biology, there are still relatively few studies of trace element concentrations in marine seawater environments. As such, we have only a cursory knowledge of what controls their distribution with depth in the water column. A brief summary of the biogeochemistry of cobalt, manganese, and iron is presented here.

Cobalt is now believed to exhibit micronutrient behavior (Saito and Moffett 2002, Saito et al. 2004) as well as characteristics associated with scavenged elements in the 
water column (Johnson et al. 1988). This combined imprint of biological and scavenging processes on the vertical profile is characteristic of hybrid-type metals (Bruland and Lohan 2004). Nutrient-like depletion of cobalt has been observed in the upper water column of several environments including the Sargasso Sea, North Pacific, Costa Rica upwelling dome, and Peru upwelling region (Martin et al. 1989, Saito and Moffett 2002, Saito et al. 2004, Saito et al. 2005). While cobalt generally behaves similarly to iron in the upper water column, it has been observed to be co-oxidized by manganese oxidizing bacteria (Tebo et al. 1984, Moffett and Ho 1996). A manganese oxidizing marine Bacillus was demonstrated to oxidize cobalt in the absence of manganese, leading to further work that suggests manganese and cobalt may be oxidized via the same biological pathway (Tebo et al. 1984, Moffett and Ho 1996). Competitive inhibition experiments confirm this theory, though it was determined that these processes occur primarily in coastal environments such as Waquoit Bay, MA, and not in the euphotic zone of the oligotrophic Sargasso Sea where biological uptake by phytoplankton dominates cobalt distribution (Moffett and Ho 1996).

Iron also behaves as a hybrid-type metal. An earlier synthesis of data noted that surface concentrations of dissolved iron are generally below $0.2 \mathrm{nM}$ with an average deep concentration of $0.76 \mathrm{nM}$ in the open ocean (Johnson et al. 1997). However, significant variability has been observed in depth profile shape and absolute concentration. For example, Sedwick et al. (2005) observed high aerosol deposition concurrent with dissolved iron concentrations reaching $1.8 \mathrm{nM}$ within a cyclonic eddy in the Sargasso Sea. These findings confirm that iron distribution in surface waters should be significantly affected by dust deposition, primary productivity, and transport processes such as advection and mixing (Sedwick et al. 2005, Boyle et al. 2005). As these factors are all known to change seasonally, there is the potential for spatial and temporal variability in dissolved iron concentrations.

Manganese is considered a scavenged element, showing elevated concentrations at the surface due to aeolian deposition and near surface redox cycling including reductive dissolution of manganese oxides (Sunda and Huntsman 1985, 1988). Rapid depletion with depth is due to sorption to sinking particles and/or oxidation by manganese-oxidizing bacteria (Emerson et al. 1982, Tebo et al.1984). Secondary 
maxima in manganese found at intermediate depths are likely due to redox reactions occurring near oxygen minimum zones (Johnson et al. 1996). Diffusion out of sediments in regions of low oxygen bottom water can also be a source of manganese to deep water (Thamdrup et al. 1994).

\subsection{Mesoscale eddies near the Hawaiian Islands}

Mesoscale eddies are ubiquitous features in the world's oceans and are hypothesized to play an essential role in processes ranging from heat transport to upper ocean ecology and biogeochemistry (e.g. Cheney and Richardson 1976, McGillicuddy et al. 1998, Oschlies and Garcon 1998; Fischer et al. 2002, Sakamoto et al. 2004). Here, we focus on the role of eddies as a mechanism by which nutrient-enriched deep waters are upwelled into lit surface waters, thereby increasing biological community production and potentially enhancing particle export to deeper waters (e.g. Benitez-Nelson et al. 2007, McGillicuddy et al. 1998, Falkowski et al.1991, McGillicuddy et al. 2007). Mesoscale eddies are produced by a variety of physical interactions, such as wind and baroclinic instabilities, but our inability to routinely predict eddy formation has made the study of these mesoscale features logistically difficult.

Wind-induced mesoscale eddies regularly occur off the leeward shores of the Hawaiian Islands throughout the year, increasing in frequency during periods of high trade wind intensity (October - March) (Patzert 1969, Lumpkin 1998, Chavanne et al. 2002, Dickey et al. this volume). These northeasterly winds are funneled through the volcanic peaks of the Hawaiian Islands, mainly Maui and Hawaii, causing divergent and convergent flow patterns at the surface that induce localized upwelling (cold-core cyclonic) and downwelling (warm-core anticyclonic) mesoscale eddies. The eddies tend to be of significant size $(\sim 180 \mathrm{~km}$ in diameter $)$ and have a typical life-span of $3-8$ months (Patzert 1969, Lumpkin 1998, Chavanne et al. 2002, Calil et al. this volume). A number of studies have demonstrated that Hawaiian lee eddies are highly productive features, resulting in large increases in primary production, plankton biomass, and even larger organisms, such as the Pacific Blue Marlin (Falkowski et al. 1991, Olaizola et al. 1993, Allen et al. 1996, Seki et al. 2001, Seki et al. 2002, Bidigare et al. 2003, Vaillancourt et al. 2003; Benitez-Nelson et al. 2007, Brown et al. this volume, Rii et al. 
this volume). Lumpkin (1998) determined that on average 9 cyclonic eddies occur each year in the lee of the Hawaiian Islands, with one eddy per month generated during the winter from 1993 to 1995 . Their regular formation therefore provides an ideal natural laboratory for investigating eddy-enhanced biological production and carbon export in an accessible subtropical oligotrophic setting.

\subsection{The Influence of Eddies on Trace Metal Biogeochemistry}

The logistical difficulties in locating eddies in combination with the potential for contamination of trace metal samples without specialized equipment aboard has led to relatively few studies on the influence of eddies on trace metal biogeochemistry. Macronutrient upwelling has been invoked as an important influence on primary productivity in the mesoscale eddies found in the Sargasso Sea (McGillicuddy et al. 1998). Cobalt depletion has been observed in the photic zone of the same region and is hypothesized to be due to the enhanced productivity associated with eddy induced upwelling (Saito and Moffett 2002). A time-series analysis of cobalt over one year showed sharp depletions of cobalt concurrent with decreases in water temperature at $\sim 44 \mathrm{~m}$, consistent with the passing of cyclonic mesoscale eddies over the region and/or mixing events. Because hybrid-type trace elements are not greatly enriched in deep water relative to surface waters as macronutrients are, upwelling cannot resupply the euphotic zone with these hybrid-type elements to the same extent as it can with macronutrients. Thus, enhanced productivity and export flux could explain the depletion of the small reservoir of cobalt observed with mixing and/or upwelling events (Saito and Moffett 2002).

The anticyclonic eddies off the western coast of Canada have lifespans of more than a year, and were recently examined for iron biogeochemistry (Johnson et al. 2005). These Haida eddies typically form in the high nutrient low chlorophyll (HNLC) region of the Gulf of Alaska, and Haida-2000 was found to entrain a large amount of iron as it moved westward from the coastal region. Total dissolved iron reached $5 \mathrm{nM}$ at $25 \mathrm{~m}$ depth and $3 \mathrm{nM}$ at $100 \mathrm{~m}$ depth during eddy formation, and was found to be 1.5-2 times higher than background concentrations even 16 months later (Johnson et al. 2005). These iron concentrations are $\sim 3$ orders of magnitude above what is generally found in this 
HNLC area (less than $0.05 \mathrm{nM}$ ). In contrast, the downwelling and isolating effects of the anticyclonic eddy Haida-2000 resulted in rapid macronutrient utilization and depletion within the eddy (Peterson et al. 2005).

Here, we present detailed analyses of cobalt, manganese and iron from the E-Flux sampling program to investigate trace metal dynamics in the presence and absence of a cyclonic eddy in the lee of the island of Hawaii. Mechanisms that may control the distribution of these trace metals are discussed as well as implications regarding their control in oligotrophic waters. Three themes are presented: 1) A potential concentrating mechanism for cobalt within cyclonic eddies, 2) the possible existence of a minimum biological productivity threshold for the formation of a cobalt and soluble reactive phosphorus correlation, and 3) the influence of island effects on trace metal concentrations in this region.

\section{Methods}

\subsection{Sampling Techniques}

During the E-Flux II cruise (January 10-27, 2005), a full trace metal sampling program was employed in the vicinity of the Hawaiian Islands within a grid of $-157.5^{\circ}$ to $-156.0^{\circ} \mathrm{W}$ and $19.7^{\circ}$ to $20.5^{\circ} \mathrm{N}$. Acid-cleaned, teflon-coated Go-Flo sampling bottles of $10 \mathrm{~L}$ and $2.5 \mathrm{~L}$ capacity (General Oceanics Inc.) were deployed on Kevlar wire aboard the R/V Wecoma at 14 stations. The 10L bottles were tripped with epoxy-coated lead messengers and reported sampling depths were based on the wire payout. The $2.5 \mathrm{~L}$ bottles were deployed on an epoxy-coated Go-Flo rosette and programmed to trip sequentially using a timer-controlled mechanism. Exact sampling depths for the trace metal rosette were recorded by a pressure sensor attached to the rosette.

During the E-Flux III cruise (March 10-28, 2005), a smaller set of trace metal samples were collected from the CTD rosette aboard the R/V Wecoma. The CTD utilized 10L X-Niskin sampling bottles on a Seabird Rosette. During this cruise, only unfiltered trace metal samples were collected because our trace metal sampling program was not aboard. Samples were collected in trace metal cleaned bottles (see below) directly from the CTD while wearing clean gloves and minimizing time that each bottle was open. The $\mathrm{X}$-Niskin bottles on the rosette were equipped with silicone rubber O-rings. The samples 
were subsampled for cobalt, then acidified upon return to the laboratory in a cleanroom environment. It should be pointed out that 10L X-Niskins, like those found on the R/V Wecoma CTD, are also used by some laboratories for trace metal sampling on Kevlar line, suggesting those bottles may not necessarily be contaminated. However, the use of a metal conducting hydrowire and lack of HEPA filtered air environment for sampling are potential sources of contamination in our E-Flux III samples. The fact that the samples appear to be uncontaminated could be related to the high frequency of CTD casts during E-Flux III (> 100 CTD casts), and the continual seawater rinsing of the rosette and hydrowire associated with each deployment. Due to the high iron content typically found in natural particulate material relative to dissolved iron and the lack of filtration of these samples, iron data for E-Flux III are not reported.

All sample bottles for storing seawater until analysis were soaked overnight in acidic detergent Citranox, rinsed thoroughly with Milli-Q water (Millipore), filled with $10 \% \mathrm{HCl}$ to soak for 10 days, and rinsed thoroughly with Milli-Q water adjusted to $\mathrm{pH} 2$ prior to use for sample storage. Immediately following collection during E-Flux II, GoFlo bottles were pressurized with $99.999 \% \mathrm{~N}_{2}$ at $\sim 5 \mathrm{psi}$, and seawater was filtered through teflon tubing and a $147 \mathrm{~mm}, 0.4 \mu \mathrm{m}$ polycarbonate sandwich filter into acid washed polyethylene and teflon sample bottles in a positive pressure class-100 clean environment. All tubing and filters were detergent and acid-soaked prior to use. During E-Flux II, samples intended for total dissolved cobalt and cobalt speciation measurements were refrigerated in the dark until analysis. Samples intended for dissolved Fe and $\mathrm{Mn}$ analyses were acidified to $\mathrm{pH} 1.7$ with high purity $\mathrm{HCl}$ (Seastar Inc.) and stored at room temperature. Samples intended for all cobalt analyses were not acidified and were kept at $4^{\circ} \mathrm{C}$ in darkness until analysis.

Samples from E-Flux III were not filtered. Manganese analyses from those samples are described as total dissolvable manganese following previously reported sample collection technique (samples were acidified to $<\mathrm{pH} 2$ and allowed to sit for several months prior to analysis, similar to Sedwick et al. 2005). Cobalt analyses from those samples are described as total cobalt because the particulate fraction in seawater is negligible and samples were UV irradiated and not acidified. E-Flux II samples, however, were filtered and iron and manganese are described as "dissolved" 
concentrations following previously reported sample collection technique (filtered samples were also acidified to $<\mathrm{pH} 2$ and allowed to sit for several months prior to analysis, similar to Sedwick et al. 2005) and cobalt concentrations are described as total dissolved cobalt and labile cobalt following previously reported data using identical sampling and processing methods (Saito and Moffett 2001, Saito et al. 2002, Saito and Moffett 2002, Saito et al. 2004, Saito et al. 2005).

During E-Flux II, Go-Flo sampling bottles on the rosette occasionally tripped at incorrect depths. To determine when this occurred, filtered nutrient samples collected from all GoFlo bottles were compared with nutrient sample data from corresponding CTD rosette casts. When nutrient values from GoFlo bottles were not oceanographically consistent with the CTD nutrient data, the trace metal sample was not used. In addition, triplicate trace metal measurements were run on samples that did not produce oceanographically consistent results to assay for processing contamination. If subsequent repeated analyses revealed a lower, more reasonable concentration, the lower number was used, assuming that the previous sample aliquot had been contaminated during analysis preparation.

\subsection{Cobalt Analyses}

Concentrations of total, total dissolved, and labile cobalt were determined using a previously described cathodic stripping voltammetry (CSV) method (Saito and Moffett 2001) both during the cruise and immediately upon returning to the laboratory. Measurements were made using an Eco-Chemie $\mu$ Autolab system connected to a Metrohm 663 VA Stand equipped with a hanging mercury drop electrode and a teflon sampling cup.

For total and total dissolved cobalt analyses, samples were UV-irradiated for $1 \mathrm{hr}$ prior to analysis using a Metrohm UV digestor which is necessary to degrade the organic ligands that bind the cobalt and allow complete binding by the added electroactive cobalt ligand dimethylglyoxime. Samples were analyzed in $8.5 \mathrm{~mL}$ aliquots with the addition of $30 \mu \mathrm{L}$ recrystalized dimethylglyoxime (DMG, $0.1 \mathrm{M}$ in methanol), $1.5 \mathrm{~mL}$ purified nitrite (1.5M in Milli-Q water), and $50 \mu \mathrm{L}$ purified EPPS buffer ( $0.5 \mathrm{M}$ in Milli-Q water).

Reagent purification protocols were identical to those previously published (Saito and 
Moffett 2001). Analysis began with a 180s purge with $99.999 \% \mathrm{~N}_{2}$. Each sample was conditioned at $-0.6 \mathrm{~V}$ for $90 \mathrm{~s}$ at a stir-rate of $2500 \mathrm{rpm}$ followed by a $10 \mathrm{~s}$ equilibration step and a linear sweep from $-0.6 \mathrm{~V}$ to $-1.4 \mathrm{~V}$ at a rate of $10 \mathrm{~V} / \mathrm{s}$ (Saito and Moffett 2001). Cobalt concentrations were determined by the standard additions technique, with initial concentrations measured in triplicate followed by four $25 \mathrm{pM}$ additions. The analytical blank was determined by analyzing seawater that had been UV-irradiated for $1 \mathrm{hr}$, equilibrated overnight with prepared Chelex ${ }^{\circledR} 100$ resin beads (Bio-Rad), and UVirradiated a second time to degrade any leached synthetic ligands (Saito and Moffett 2001). Blanks were run at the beginning and end of the sample analyses, averaged, and used to adjust reported concentrations. Averaged blank concentrations for this dataset were $3.4 \mathrm{pM} \pm 2.0(\mathrm{n}=5)$ and $5.6 \mathrm{pM} \pm 1.4(\mathrm{n}=8)$ depending on the reagent batch used. Two suites of reagents were used during the analysis process, and the reagent batch was noted and the concentrations were adjusted according to the blank calculated for that suite of reagents. Selected samples were run in triplicate to verify their concentrations. The precision of this method is excellent. For example, mean and standard deviation of triplicate analyses of a near surface water sample gave a concentration of $32 \pm 0.7 \mathrm{pM}$.

For labile cobalt analyses, $8.5 \mathrm{~mL}$ of sample was pipetted into an acid washed teflon vial that was preconditioned with a small aliquot of the sample water. $30 \mathrm{uL}$ of DMG were added to the vial and allowed to equilibrate overnight in the dark prior to analysis (Saito et al. 2004). Analyses were then performed as described for total concentrations with the addition of the remaining two reagents and use of the standard addition technique. Previously, we determined that natural cobalt ligands in seawater have a conditional stability constant of $>10^{16.8}$ (Saito et al. 2005). This suggests that the cobalt is bound very tightly to the cobalt ligands. Thus we can define labile cobalt as the fraction of total dissolved cobalt that is either bound to weak organic and inorganic ligands in seawater or present as free $\mathrm{Co}(\mathrm{II})$, and is thus exchangeable with the complexing agent (DMG) used for analysis (Saito et al. 2004, Saito et al. 2005). The difference between the total dissolved cobalt and the labile cobalt can then be used as an estimation of the strong cobalt ligand concentration. All samples measured for labile cobalt were filtered. Analytical blanks for labile measurements were calculated by the same method used for total and total dissolved measurements. 


\subsection{Iron and Manganese Analyses}

Total dissolvable and dissolved iron and manganese were measured using inductively coupled plasma mass spectrometry as recently described in detail (ICP-MS, Saito and Schneider 2006). Briefly, 13.0mL aliquots of acidified seawater were weighed into acid-leached polypropylene centrifuge tubes, to which $100 \mathrm{uL}$ of an ${ }^{57} \mathrm{Fe}$ solution was added and allowed to equilibrate overnight. Concentrated ammonia (Seastar) was added to induce $\mathrm{Mg}(\mathrm{OH})_{2}$ and trace metal co-precipitation into a pellet. This was accomplished by allowing a precipitate to form for 3 minutes, followed by centrifugation for 3 minutes at 3000rpm (1460 x g) using an Eppendorf Centrifuge 5810R. The supernatant was decanted, the sample was centrifuged a second time to further remove residual seawater, and the pellet was re-dissolved in $500 \mathrm{uL}$ of $5 \%$ Nitric Acid (Seastar) with trace amounts of indium. The 5\% nitric acid resuspension solution was used as a blank, and signal suppression due to matrix effects was adjusted for by using a ratio of the indium signals for the blank and sample to calibrate the effective blank of each isotope for each sample. All samples were run in duplicate. SAFe seawater intercalibration standards were analyzed for iron with the surface (S1) and deep samples (D2) yielding values of $0.10 \mathrm{nM}$ and $0.86 \mathrm{nM}$, respectively, which are within the reported ranges of $0.097 \pm 0.043 \mathrm{nM}$ and $0.91 \pm 0.17 \mathrm{nM}$ (Johnson et al., 2007).

\section{$2.4{ }^{234}$ Th analyses}

Profiles of total ${ }^{234} \mathrm{Th}$ were collected from the center of Cyclone Opal (E-Flux III) from 6 separate casts using a CTD rosette with 10-L Niskin-like bottles. Sample depths ranged from $0-400 \mathrm{~m}$ at each IN station. ${ }^{234} \mathrm{Th}$ samples were processed using the 4-L manganese oxide co-precipitation technique described in detail by Pike et al. (2005) and Rutgers van der Loeff et al. (2006). ${ }^{234}$ Th samples were counted directly on a 5-sample gas-flow proportional low-level RIS $\varnothing$ beta counter for at least 12 hours or until counting errors were $<3 \%$. Samples were then recounted after $>150$ days ( $\sim 6$ half lives) since collection to precisely determine background count rates, which averaged $0.51 \pm 0.05$ cpm. After background recounting, total ${ }^{234} \mathrm{Th}$ samples were purified using ion exchange chemistry. Recovery of the added ${ }^{230}$ Th yield monitor was quantified by inductively 
coupled plasma-mass spectroscopy with addition of a ${ }^{229} \mathrm{Th}$ internal standard (Pike et al. 2005, Rutgers van der Loeff et al. 2006). Corrections were applied to ${ }^{234} \mathrm{Th}$ activities based on the ${ }^{230} \mathrm{Th}$ recovery for each sample, which averaged $0.89 \pm 0.06$. All data are decay corrected to the time of collection and reported with a propagated error that includes uncertainties associated with sampling uncertainty, counting, and other calibration errors. Water column activity of the parent ${ }^{238} \mathrm{U}$ was calculated from salinity data $\left({ }^{238} \mathrm{U} \mathrm{dpm} \mathrm{L}^{-1}=0.0686 \times\right.$ salinity; Chen et al. 1986).

\section{Results and Discussion}

\subsection{Oceanographic properties}

In 2004-2005, the E-Flux program conducted three cruises to study eddies that form regularly in the lee of the Hawaiian Islands. We present trace metal data from the second and third of these cruises, focusing on data collected from E-Flux II (W0501B), and three unfiltered vertical profiles from E-Flux III (W0503B). E-Flux III sampled a large mesoscale eddy, Cyclone Opal, while E-Flux II focused on the eddy generation region, but had no clear eddy signals. Shallow stations were sampled to $\sim 400 \mathrm{~m}$, while the stations discussed in detail here (E-Flux II: 50, 81 and E-Flux III: In 1, In 3, Out 1) were all sampled to between 1200 and $1500 \mathrm{~m}$. Station locations and regional bathymetry are shown in Figures 1a and 1b. A total of 112 cobalt samples were analyzed for total dissolved cobalt and labile cobalt from E-Flux II with selected dissolved iron and dissolved manganese measurements, and three depth profiles were analyzed for total cobalt and total dissolvable manganese collected from E-Flux III. The chemistry of this area is characterized by oligotrophic waters uniquely affected by both island effects and hydrothermal activity that are likely to contribute to trace metal concentrations (Chase et al. 1980, Boyle et al. 2005).

\subsection{General Upper Water Column Metal Concentrations Among the Hawaiian Islands}

Total dissolved cobalt, dissolved iron, and dissolved manganese were measured throughout the water column during E-Flux II with a focus on cobalt biogeochemistry. A compilation of all cobalt samples demonstrates depletion in surface waters $(\sim 0-200 \mathrm{~m})$ likely due to biological utilization in the vicinity of the Hawaiian Islands along Transect 6 
(Figures 2a and 2b). Cobalt gradually increases with depth in all profiles until 400 to $600 \mathrm{~m}$, consistent with our previous reports of a nutrient-like profile for this element (Saito and Moffett 2001, Saito and Moffett 2002, Saito et al. 2002, Saito et al. 2004, Saito et al. 2005).

Surface water cobalt appears to have significant temporal variability. During the E-Flux II cruise there were a few station locations that were revisited (Figure 1a), including: $20.5^{\circ} \mathrm{N},-157.5^{\circ} \mathrm{W}$ (90 and 100 : sampled 1 day apart) $20.27^{\circ} \mathrm{N},-156.8^{\circ} \mathrm{W}(81$ and 58: sampled 4 days apart), and $20.15^{\circ} \mathrm{N},-156.82^{\circ} \mathrm{W}$ (60 and 74: sampled 3 days apart). All three sites showed different surface cobalt concentrations from one sampling date to another, indicative of temporal variability on time scales as short as a few days. The replicate stations were sampled within 1 to 4 days of each other, and surface cobalt concentrations vary by up to $\sim 20 \mathrm{pM}$. This variability is likely related to changes in physical processes such as water mass movement, as well as changes in the distribution of cobalt due to biological uptake. This variability may also be due to aeolian deposition as cobalt has been observed to be affected by aeolian input in some regions such as the Mediterranean and off the coast of North Africa in the Atlantic (Herrera-Melian et al. 1994). However, the abundance of cobalt in crustal material is significantly lower than that of iron (Co:Fe ratio in crustal composition is 1:2600; Taylor and McLennan, 1985), which suggests that much larger fluxes of dust and/or higher dust solubility may be necessary to create a significant cobalt source to the upper water column.

The abundance of manganese and iron in the upper water column near Hawaii is believed to be seasonally affected by high dust input in the spring, (March-June) with lower temporal aerosol concentrations observed between July and January (Parrington et al. 1983, Perry et al. 1999, Johnson et al. 2003). During the E-Flux II cruise, dissolved manganese in the upper water column followed the expected trend of previous studies (Johnson et al. 1996): it is present in higher concentrations $(\sim 2 \mathrm{nM})$ in the surface waters presumably due to aeolian deposition, and is depleted quickly with depth due to sorption to sinking particles and/or manganese oxidizing bacteria below the euphotic zone (Figure 3a). Our data are generally oceanographically consistent with previously reported dissolved manganese concentrations that have ranged from $1.75 \mathrm{nM}$ to $<0.3 \mathrm{nM}$ at Station ALOHA (Boyle et al. 2005). 
We observed significant iron depletion in the upper tens of meters, consistent with the lower relative dust input in January and biological utilization of iron by phytoplankton (Figure 3b). The range of dissolved iron concentrations during the E-Flux II cruise are somewhat higher $(0.18$ to $1.5 \mathrm{nM}$, Figure $3 \mathrm{~b})$ than observed at Station ALOHA (below detection limit to 1nM; Boyle et al., 2005). We believe this is likely due to the closer proximity to the Hawaiian Islands and associated island effects. Comparisons with studies done during the PlumEx experiment near the Galapagos Islands are consistent with this reasoning, where surface iron was generally found to be low in surface waters except near the islands (Gordon et al. 1998). In that study, transects identified the source of iron to be upwelling from the Equatorial Undercurrent. In addition, some of the increase, though a small component of the upwelled iron, was attributed to interaction of the Equatorial Undercurrent with shallow island topography resulting in higher particulate iron concentrations (Gordon et al. 1998). In contrast to iron, surface water cobalt did not appear to be influenced by island effects and did not show any significant increases near the Galapagos Islands (Saito et al. 2004) or near the Hawaiian Islands (this study, Figure 3c). This difference between iron and cobalt in

surface waters may be due to the much lower abundance of cobalt in crustal material than that of iron mentioned above, hence requiring much more particulate resuspension or aeolian deposition from island material to noticeably elevate surface cobalt concentrations (Saito and Moffett 2002). This also has implications for time series studies near volcanic islands suggesting island proximity effects may have a particular influence on surface water iron.

\subsection{An Eddy Influence on Cobalt: Biological Entrainment and Concentrating Mechanism}

There have only been a few studies that focus on the potential influence of eddies on trace metal distributions (Saito et al. 2002, Johnson et al. 2005, Sedwick et al. 2005). It is now becoming clear that there are multiple possibilities for trace metal distributions depending upon the specific nature of the eddy. As mentioned earlier, we observed depletion of cobalt concurrently with decreases in water temperature that we interpreted as being associated with the passing of a cyclonic eddy or mixing events in the Sargasso Sea during a 1999 time series (Saito and Moffett 2002). This depletion likely occurs due 
to a combination of macronutrient upwelling and the resulting increase in phytoplankton growth (McGillicuddy et al. 1998). In this case, upwelling of macronutrient rich waters does not replenish the depleted surface water cobalt because cobalt's hybrid-type vertical profile has so little cobalt to be upwelled from depth due to its continual scavenging in intermediate and deep waters. A coastal anticyclonic eddy in the North Pacific was observed to show a very different mechanism for an eddy influence on trace metal distributions (Johnson et al. 2005). The coastal formation of this eddy entrained significant dissolved and particulate iron, transporting it into the iron limited region of the North Pacific while macronutrients were drawn down due to eddy isolation from surrounding waters (Peterson et al. 2005). In addition to these eddy-related mechanisms controlling trace metal distributions (a macronutrient upwelling-associated depletion process, and a transport and containment process), we now propose a third type suggested by this study: a mechanism for concentrating cobalt from intermediate waters into the upper water column.

Three vertical cobalt profiles taken during examination of Cyclone Opal from EFlux III show an increase in cobalt concentrations inside the eddy relative to outside the eddy (Figure 4). The integrated inventories of cobalt between 5 and $100 \mathrm{~m}$ also show higher cobalt within the eddy with values of $2.5 \mu \mathrm{mol} \mathrm{Co} \mathrm{m}{ }^{-2}$ and $2.0 \mu \mathrm{mol} \mathrm{Co} \mathrm{m}{ }^{-2}$,

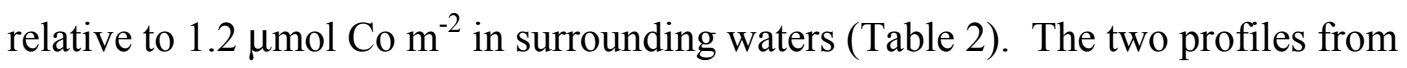
within the eddy also show small maxima at $100 \mathrm{~m}$ in both profiles, whereas no such maximum is present in the Out station. These differences in cobalt abundances are resolvable since the detection limit for this voltammetry method is $\leq 3 \mathrm{pM}$ (Vega and van den Berg 1997, Saito and Moffett 2002). We attribute the maxima to shallow and extensive remineralization occurring at that depth. This is supported by three datasets: 1) ${ }^{234}$ Th flux data (Figure 5 and Maiti et al. this volume), 2) microscopy observations of remineralization (Benitez-Nelson et al. 2007), and 3) absence of a significant organic export flux (Benitez-Nelson et al. 2007). Despite a significant increase in primary productivity, Cyclone Opal did not produce a large organic export flux; on the contrary, near complete remineralization of sinking organic matter was observed at $\sim 100 \mathrm{~m}$, with sinking diatom frustules appearing to have little remaining organic matter associated with them, thus preventing significant particle export of organic matter $\left(1.1 \mathrm{mmol} \mathrm{C} \mathrm{m}^{-2} \mathrm{~d}^{-1}\right.$ 
outside Opal versus $1.8 \mathrm{mmol} \mathrm{C} \mathrm{m}^{-2} \mathrm{~d}^{-1}$ inside Opal, Benitez-Nelson et al. 2007). This is consistent with the accumulation of dissolved organic carbon which accounted for $\sim 85 \%$ of the measured primary production within Cyclone Opal. Similar results were obtained using mass balance estimates of inorganic carbon (Chen et al. this volume). The nitrate + nitrite and phosphate values measured within the upper 110m of cyclone Opal also showed accumulation with remineralization within the eddy, with an integrated inventory of $91 \mathrm{mmol} \mathrm{N} \mathrm{m}^{-2}$ and $17.1 \mathrm{mmol} \mathrm{P} \mathrm{m}^{-2}$ within the Opal relative to $24 \mathrm{mmol} \mathrm{N} \mathrm{m}^{-2}$ and $9.8 \mathrm{mmol} \mathrm{P} \mathrm{m}^{-2}$ in surrounding waters (Benitez-Nelson et al. 2007). We propose that sinking particulate cobalt is similarly being remineralized before export.

These observations from Cyclone Opal suggest that there is a mechanism at work, where cobalt is concentrated within the eddy by a succession of processes: supply of cobalt to the upper euphotic zone, biological utilization of cobalt and its export in particles, and shallow and significant remineralization of cobalt from organic matter, as illustrated in Figure 6. The likely source of cobalt to the euphotic zone is upwelling, however, lateral advection and/or aeolian deposition are also plausible sources. We can calculate the amount of cobalt delivered to the upper water column by upwelling within cyclone Opal and compare it with the changes in inventory we have observed. Examination of isopyncal surfaces on a transect across the cyclone Opal with the stations we have focused on (Nencioli et al, this volume; Benitez-Nelson 2007; and Figure 4) showed isopyncal uplift of $\sim 75 \mathrm{~m}$ at In station 1 . Integrating the cobalt inventory from $75-175 \mathrm{~m}$ at Out station 1 yielded $2.0 \mu \mathrm{M} \mathrm{m}^{-2}$, compared to $2.5 \mu \mathrm{M} \mathrm{m}^{-2}$ for the top $100 \mathrm{~m}$ of In Station 1. These calculations are thus consistent with upwelling as the primary source of cobalt to the euphotic zone. However, the upper 100m inside cyclone Opal has 25\% more cobalt than can be explained by one-time eddy-induced upwelling, suggesting three possibilities: 1) that the excess cobalt may have been concentrated from the displaced pre-existing water mass and then added to the sampled water mass by the proposed biological concentrating mechanism, 2) additional eddy-induced upwelling may have occurred and the cobalt was similarly concentrated, or 3) other sources such as lateral advection and aeolian deposition contributed to the cobalt inventory. The presence of the described small remineralization peaks in the two cobalt profiles from within cyclone 
Opal (Figure 4) are consistent with the first and second interpretations, although we cannot discount the third possibility of alternate sources.

This concentrating mechanism could be especially relevant to hybrid-type elements because their oceanic reservoirs are quite small (due to low deepwater concentrations and lack of intermediate and deepwater accumulation), and hence the remineralization signature can make a significant impression on the vertical profile of the trace element. While this process is certainly not exclusive to hybrid-type elements, the impact of these signatures on the overall distributions of macronutrients and nutrient-type trace metals is relegated to a subtle one because of their much larger oceanic inventories due to accumulation during thermohaline circulation. In addition, if the remineralization were somewhat deeper, as is often expected outside of eddy environments, any small maxima would be masked by the higher concentrations associated with the much larger marine inventories of those elements. It is this combination of eddy induced upwelling, shallow and efficient remineralization, and the hybrid-type metal scarcity in intermediate waters that creates and allows us to observe this hybrid-type metal concentrating effect.

\subsection{The Upper Water Column Cobalt-Phosphate Correlation: A Mechanistic}

\section{Explanation and a Minimum Productivity Threshold}

The nutrient-like process influencing cobalt distributions in the upper water column is likely related to the role of cobalt as a micronutrient for phytoplankton and the microbial communities. We and others have previously described correlations of total dissolved cobalt and soluble reactive phosphorus (described as phosphate or P herein) in the Gulf of Alaska, Peru upwelling region, and Equatorial Atlantic (Sunda and Huntsman 1995, Saito and Moffett 2002, Saito et al. 2004). Recent results also show this cobalt and phosphate correlation to be found in the Ross Sea and throughout the North Pacific and Bering Sea (Saito and Noble in prep., Saito et al. in prep.). These findings are similar to the correlations seen between other trace metals and macronutrients, such as cadmium with phosphate and zinc with silica (e.g. Boyle et al. 1976, Bruland 1980, and Cullen et al. 2003), with the important exception that those micro- and macro-nutrient pairs correlate throughout the water column, whereas cobalt and phosphate only correlate in the upper ocean. Cobalt and phosphate appear to be decoupled, however, in the Sargasso 
Sea and the Western Atlantic shelf/slope area (Saito and Moffett 2002), presumably due to a combination of extremely oligotrophic conditions in the Sargasso Sea and coastal inputs in the shelf/slope area, which result in a cobalt-salinity correlation instead. In addition, the slopes of these cobalt-phosphate relationships, which imply their relative utilization rates ( $\Delta \mathrm{Co} / \Delta \mathrm{P}$; Redfield 1958 , Sunda and Huntsman 1995$)$, vary significantly from region to region from $27 \mu \mathrm{mol} \mathrm{Co} \mathrm{mol}{ }^{-1} \mathrm{P}\left(\mathrm{r}^{2}=0.83\right)$ in the Ross Sea (Saito and Noble unpublished results) to $560 \mu \mathrm{mol} \mathrm{Co} \mathrm{mol}{ }^{-1} \mathrm{P}\left(\mathrm{r}^{2}=0.63\right)$ in the Equatorial Atlantic (Saito and Moffett 2002), with the Peru upwelling region (248 $\mu \mathrm{mol} \mathrm{Co} \mathrm{mol}^{-1} \mathrm{P}$ ), Northeast Pacific (36-40 $\mu \mathrm{mol} \mathrm{Co} \mathrm{mol}^{-1} \mathrm{P}$ ) and this study (see below) falling within this range (Saito et al. 2004, Sunda and Huntsman 1995).

In E-Flux II, there is a weak relationship between $\mathrm{Co}$ and $\mathrm{P}$ in the upper water column (shallower than $300 \mathrm{~m})\left(\mathrm{r}^{2}=0.63, \Delta \mathrm{Co} / \Delta \mathrm{P}=29 \mu \mathrm{mol} \mathrm{Co} \mathrm{mol}^{-1} \mathrm{P}, \mathrm{n}=35\right.$, Figure 7a). Note that this does not take DOP into account due to limited data and information on bioavailability at this time (Karl and Yanagi 1997). In contrast, the E-Flux III cobalt dataset above $250 \mathrm{~m}$ produces a strong correlation $\left(\mathrm{r}^{2}=0.91, \mathrm{n}=17\right)$ between cobalt and phosphate with a $\Delta \mathrm{Co} / \Delta \mathrm{P}$ of $37 \mu \mathrm{mol} \mathrm{Co} \mathrm{mol}^{-1} \mathrm{P}$ (Figure $7 \mathrm{~b}$ ). The variability in Co:P data from E-Flux II does not appear to be due to analytical or sampling errors, phosphate analyses were compared between discrete samples taken at comparable depths from both the trace metal sampler and CTD and showed excellent agreement (Figure 3e). In addition, since samples from E-Flux III were unfiltered, there is the possibility that the particulate fraction caused the Co:P correlation. However, we and others have previously observed Co:P correlations in the dissolved fraction (Martin et al. 1989, Saito and Moffett 2002, Saito et al. 2004), and the component of cobalt associated with particles is generally quite small when compared to typical dissolved concentrations (Sherrell and Boyle 1992). For example, particulate cobalt is estimated to be only $\sim 2.6 \%$ of total dissolved cobalt at $100 \mathrm{~m}$ and $\sim 1.6 \%$ of total dissolved cobalt at $1500 \mathrm{~m}$ near Bermuda (data from Saito 2002 in combination with Sherrell and Boyle 1992). The cobalt concentrations measured in E-Flux III were comparable to those of E-Flux II, which is also consistent with a relatively small particulate fraction of cobalt.

This Co:P correlation in surface waters has only recently been recognized (Sunda and Huntsman 1995, Saito and Moffett 2002, Saito et al. 2004) and the question of why 
cobalt and phosphate are coupled as nutrients in some areas and decoupled in others has yet to be directly addressed. The geochemistry of phosphate is typically dominated by biological processes in the upper water column (e.g. Redfield 1958, Bronk et al. 1994, Tyrell 1999, Benitez-Nelson 2000). As mentioned earlier, cobalt is affected both by abiotic and biological processes, and it is logical that the extent to which biology controls cobalt should control the correlation between cobalt and phosphate. The small inventory of cobalt (less than $0.1 \mathrm{nM}$ in most deep waters and even less in surface waters) is likely critical to its high variability, and hence biological processes of even moderate amplitude could have a major influence on cobalt geochemistry. The size of this inventory is evident when compared to other elements: cobalt concentrations in deep waters are only 2-3 times higher than in surface waters, where phosphate concentrations are 25-30 times higher and zinc and cadmium have an even greater discrepancy ( $>100$ fold).

The influence of each biotic and abiotic source and sink of cobalt can be considered as a vector in cobalt-phosphate space to demonstrate the tug-of-war between processes on cobalt's geochemistry (Figure 9a). This decomposition of processes into vectors should also apply to other hybrid-type trace metals (HTMs), in particular iron. The aeolian deposition of cobalt that has been reported in some locations (Wong et al. 1995, Herrera-Melian et al. 1994) would result in a noticeable increase in cobalt with no observable increase in phosphate (shown as an upwards vector in Fig 9a). There are also microbial oxidation pathways for manganese and cobalt that may remove cobalt from coastal waters independently of phosphate, resulting in a downward biotic scavenging vector, where in this case biotic scavenging refers to microbial cobalt oxidation and not utilization as a micronutrient (Tebo et al. 1984, Moffett and Ho 1996, Saito et al. 2004). Other abiotic scavenging processes would also likely result in the preferential removal of hybrid-type metals such as Co relative to $\mathrm{P}$ in the water column and a downward vector. Interestingly, because scavenging depletes cobalt relative to phosphate in intermediate and deep waters, the upwelling of water masses results in a range of vectors (depending on the extent of scavenging) with a lower Co:P slope than found in the upper water column (Figure 9a).

Biological activity in the upper water column can be broadly described by a diagonal line in this vector diagram, similar to the correlation of Co:P that we have 
observed. This line encompasses two diagonal vectors, biological utilization of cobalt as a micronutrient (downwards), and remineralization (upwards). Both of these vectors also involve uptake and release of phosphate. The slope of the biological utilization vector can be considered as the composite cellular quota of the biological community for the hybrid-type metal and phosphate in the surrounding waters (Figure 9b). This range of biological cellular quotas is visualized by a group of arrows each symbolizing an important phytoplankton group in the community (Figure 9a). Together this phytoplankton community acts to entrain cobalt into a micronutrient geochemical role and creates the composite $\mathrm{Co:P}$ of the structure we observe. Little is known about hybrid-trace metal remineralization relative to phosphorus at this point, but presumably hybrid-type metals and phosphate are both remineralized relatively efficiently in order to support the observed upper water column correlations (e.g. Strzepek et al. 2005). Alternatively, incorporation of trace elements into biogenic minerals such as opal is believed to be a relatively small reservoir at this time (e.g. zinc in diatom frustules, Ellwood and Hunter, 1999). Presumably, if the phytoplankton community structure remains consistent (as well as the associated average cellular quota), uptake and remineralization of cobalt and phosphate should not affect the HTM:P slope, only the movement up or down the diagonal HTM:P line.

The Co:P correlation in the upper water column is beginning to appear to as a common oceanographic feature with the notable exception of oligotrophic regions such as the Sargasso Sea and coastal environments (Saito and Moffett, 2002). The site of this study occurs in the North Pacific oligotrophic gyre, yet is clearly influenced by island and eddy effects, and hence could be considered a transition from an oligotrophic system to a moderately more productive one. When one compares the various vectors in cobaltphosphate space described above and in Figure 9a, it is clear that a correlation between these two nutrients would form when the two biological processes of uptake and remineralization dominate over the remaining processes of aeolian deposition, upwelling, and scavenging ([uptake + remineralization] $>>$ [dust + upwelling + scavenging]). Uptake and remineralization work along the HTM:P line, whereas dust and scavenging work along the vertical axis. The former tend to enhance correlations, whereas the latter tend to dilute them. Upwelling ranges from nearly horizontal (upwelling deep water with 
high $\mathrm{P}$ and low $\mathrm{Co}$ ), to slightly inclined (upwelling from shallower depths where there is some Co:P correlation). We believe the waters sampled during our E-Flux II and III cruises may have been transitioning to such a system where biological uptake and remineralization began to dominate over those other processes, perhaps due to the combination of eddy and island induced increases in productivity. This interpretation suggests that there is a minimum productivity threshold above which the formation of a Co:P correlation occurs in the upper water column. While it is tempting to try to assign a specific productivity value for this correlation, it is clearly dependent on the relative magnitude of the aeolian deposition, upwelling, and scavenging, all of which can vary significantly between environments.

There is evidence for this increase in biological processes controlling uptake and remineralization by cyclone Opal. The chlorophyll concentrations in the photic zone during E-Flux III are considerably higher than those during E-Flux II (Figure 8, and Rii et al. this volume). Primary productivity and particulate organic carbon (POC) data were not available for E-Flux II, however comparison of primary productivity and biomass for In and Out stations during the study of Cyclone Opal provide a range for the proposed threshold. Primary productivity inside Opal was determined to be $\sim 128 \mathrm{mmol} \mathrm{C} \mathrm{m}^{-2} \mathrm{~d}^{-1}$ based on phytoplankton growth and $\Delta^{18} \mathrm{O}$ data, compared to $\sim 46 \mathrm{mmol} \mathrm{C} \mathrm{m}{ }^{-2} \mathrm{~d}^{-1}$ determined for outside Opal (Benitez-Nelson et al. 2007). Estimated phytoplankton biomass revealed an inventory of $220 \mathrm{mmol} \mathrm{C} \mathrm{m}^{-2}$ within Opal compared to $114 \mathrm{mmol} \mathrm{C}$ $\mathrm{m}^{-2}$ in surrounding waters (Benitez-Nelson et al. 2007). Fucoxanthin, an accessory pigment of diatoms, had large inventory changes from outside to inside Opal, highlighting the impact of a strong diatom bloom on aggregate biomass estimates $(5.5 \mathrm{mg}$ $\mathrm{m}^{-2} \mathrm{In}, 1.0 \mathrm{mg} \mathrm{m}^{-2}$ Out) (Benitez-Nelson et al. 2007). In general, Cyclone Opal resulted in greater primary productivity and a shift in species composition including the significant presence of diatoms, and both findings could have contributed to the concentrating mechanism as well as the entrainment of cobalt as a micronutrient.

There is likely a temporal component to the formation of the Co:P correlation that could be occurring on a timescale of weeks to months. This is consistent with our data where a weak correlation is observed during the earlier cruise (E-Flux II). However, the higher cobalt values from the Out station of the cyclone Opal E-Flux III cruise still fall 
on the Co:P line (Figure 7), suggesting the upper water column in the region may have been sufficiently "biologically entrained" since the previous cruise to allow formation of the Co:P correlation.

As mentioned above, large variations of Co:P slopes have been observed in different environments (e.g. Saito et al. 2004). In the Peru upwelling region, a large change in Co:P slope was observed when the complexation of cobalt changed significantly, with a much higher slope when significant labile cobalt was present (Saito et al. 2004). This suggests that the bioavailability of hybrid-type trace metals, in addition to the average community cellular quota described above, may also be important in controlling the HTM:P slope. The relative abundance of cobalt and zinc, via biological substitution in metalloenzymes, could also influence this slope (Sunda and Huntsman 1995, Saito et al. 2002). In summary, small changes in biological productivity, biological diversity, bioavailability, and scavenging components in the water column may have large effects on the distribution of HTMs and their distribution relative to phosphate.

\subsection{The Implications of a Biological Concentrating Mechanism for Hybrid-Type Metals}

The small marine inventories of hybrid-type metals results not only in their tendency to limit productivity (e.g. iron limitation), but they also leave the distributions of those elements relatively "exposed" to the influences of individual processes. In contrast, an element or nutrient with a much larger inventory (e.g. Zn, Cd, Ni, nitrate, phosphate) is "buffered" against observable effects of such processes by the larger seawater reservoirs. As a result, any biotic or abiotic processes could presumably have a significant influence on the distribution because the change in cobalt concentration is significant relative to the cobalt already present. For example, $0.3 \mathrm{pmol} \mathrm{L}^{-1} \mathrm{~d}^{-1}$ of biological uptake (Saito et al. 2004) relative to a typical surface water $20 \mathrm{pM}$ dissolved cobalt concentration is a significant fraction of the total cobalt. If that cobalt is taken up by the biota and remineralized at the $100-300 \mathrm{~m}$ depth, it will be evident as a peak since the concentrations at this depth are only 50pM. Cd and $\mathrm{Zn}$, however, would not show a peak since their concentrations at those depths are in the nanomolar range for $\mathrm{Cd}$ and $\mathrm{Zn}$ ( $\sim 1 \mathrm{nM}$ and $\sim 8 \mathrm{nM}$, respectively). The concentrating process we propose here is likely 
not specific to eddies, but the combination of upwelling, shallow remineralization, isolation from surrounding waters, and large number of analyses, has helped to identify it.

One potential criticism of this concentrating mechanism is that if cobalt and phosphate are correlated, why would cobalt be concentrated in the upper water column while macronutrients or non-hybrid-type micronutrients are not? The answer to this critique is that those elements must also be affected similarly, but their much larger marine inventories make the resulting effects relatively small and hence they are likely obscured by the much higher concentrations at depth. For the hybrid-type elements such as cobalt and iron, however; this concentrating effect is likely significant and may be important for overall oceanic distributions. While we do not have iron data from E-Flux III, there does appear to be a shallow maxima in our iron data from the E-Flux II cruise, suggesting that such processes may be important for iron as well, even at lower productivities (Figure 3b). In the coming years, improving our understanding of the competing controls on hybrid-type trace metals will continue to be a high priority.

\subsection{Intermediate Water Column Results}

A maximum in cobalt concentration was observed at 400 to $600 \mathrm{~m}$ depth during both E-Flux II and E-Flux III (Figures 2a and 10b). To a lesser extent, a deeper maximum was also present for manganese and perhaps iron at $\sim 600-700 \mathrm{~m}$ depth (Figures $3 \mathrm{a}$ and $3 \mathrm{~b}$ ). Two plausible sources for these maxima are hydrothermal input and/or island effects. The influence of hydrothermal sources on intermediate depth trace metal concentrations has been reported for the nearby Hawaiian Ocean Time-series station ALOHA (Boyle et al. 2005). In that study, helium $\left(\delta^{3} \mathrm{He}\right)$ served as a proxy for a hydrothermal signal, and enhanced dissolved iron concentrations were attributed to hydrothermal activity at Loihi Seamount. At this time, it does not appear that the cobalt signal observed in the lee of the Hawaiian Islands was from a hydrothermal source due to the large difference in depth of signals: the iron concentration feature found at Station ALOHA was identified at approximately $1000-1500 \mathrm{~m}$ depth, similar to the $\left({ }^{3} \mathrm{He}\right)$ signal and depth of Loihi Seamount (Boyle et al. 2005). While the small manganese and iron maxima may be associated with hydrothermal activity, the cobalt feature we observed between Maui and Hawaii was significantly shallower (400 to $600 \mathrm{~m}$ ) than the summits of 
Loihi and the nearby Mahukona Seamount, which is likely extinct (Garcia et al. 1990, Moore and Clague 2004). It is improbable that the cobalt feature has a hydrothermal source without an explanation for transport across isopycnals.

Given the proximity of the E-Flux study sites to Hawaii and Maui, the islands and their associated shelf areas are the most likely sources of trace metals to the water column. As shown in the bathymetry data in Figure 1b, there is a substantial shelf at $\sim 400-600 \mathrm{~m}$ depth particularly around the islands of Maui, Kahoolawe, Molokai, and Lana'i. Circulation of water masses between the islands may entrain significant concentrations of metals at the depth of the observed cobalt maxima. Mn has been invoked as a tracer of sedimentary input and lateral advection (Martin et al. 1985), although secondary maxima in Mn have been convincingly argued to be the result of in situ redox processes in oxygen minimum zones (Johnson et al. 1996). Since the water column is well oxygenated here, a sedimentary source seems more likely. In addition, it is possible that the Hawaiian eddies themselves contribute to this entrainment process. The cyclonic circulation of Cyclone Opal penetrated to greater than $250 \mathrm{~m}$ depth, with water masses observed to maintain some cyclonic circulation to the $400 \mathrm{~m}$ maximum depth of ADCP measurements (Nencioli et al. this volume). Cyclone Opal also had a symmetrical shape with a diameter of $\sim 150 \mathrm{~km}$, large enough for its edges to come into contact with the shelves associated with Maui and Hawaii.

Interestingly, the chemical speciation of cobalt in this intermediate depth maximum shows only a small increase in labile cobalt relative to the total dissolved fraction, implying that this putative shelf source is releasing a non-labile form (Figure $3 c)$. This is in contrast to our previous studies in the Peru upwelling system, where we observed labile cobalt and proposed that it was being released from a sedimentary source through microbial reduction of manganese oxide and simultaneous low bottom water oxygen concentrations that prevented microbial reoxidation of cobalt and manganese before sedimentary escape (Saito et al. 2004 and references therein). Given that the intermediate depth waters near the Hawaiian Islands are well-oxygenated, it suggests that the mechanism for cobalt release from the shelf environment may be distinct from that of the Peru upwelling region. We speculate that the mechanism for release of complexed 
cobalt at this depth may be due to remineralization of organically complexed cobalt from organic matter on the shelves.

Manganese in the deeper waters typically displays depletion due to scavenging by sinking particles and/or microbial oxidizing activity. Our Mn depth profiles are consistent with previously reported concentrations by Boyle et al. (2005) with the exception of the above mentioned small maximum. In addition to the iron maxima mentioned above, iron concentrations we measure in the intermediate waters are somewhat higher (0.68-1.48nM) than those observed by Boyle et al. $(0.50-1.00 \mathrm{nM}$; 2005), perhaps due to closer proximity to either island/sedimentary sources or hydrothermal sources. We are not aware of $\delta^{3} \mathrm{He}$ data from between the Hawaiian Islands that would allow us to confirm any hydrothermal signatures found from this region. These higher iron values appear to be real, given our successful intercalibration with the surface and deepwater SAFe standards (Johnson et al. 2007). We did not observe a peak in Fe at 400 to $600 \mathrm{~m}$ depth as we did for cobalt; however, this may be due the rapid scavenging of iron in seawater (Wu and Luther 1995) relative to cobalt, which might prevent an iron signal from appearing beyond immediate proximity with the shelf. We believe that this is a reasonable hypothesis given previous evidence suggesting the mechanisms for sedimentary release of cobalt and iron are different (Saito et al. 2004, Johnson et al. 1988).

\section{Conclusions}

We have identified processes that affect the biogeochemistry of cobalt, manganese, and iron in both the surface and intermediate waters surrounding the Hawaiian Islands. We suggest that the shallow and near complete remineralization of sinking POC within Cyclone Opal resulted in a Co:P correlation and an accumulation of cobalt in the upper water column. This potential concentrating mechanism may be a general process important to the hybrid-type metals throughout the oceans. A change in Co:P correlation from January to March was observed, which we suggest may be due to a minimum primary productivity threshold. In addition, a cobalt maximum at 400 to $600 \mathrm{~m}$ was found for all stations studied. This was attributed to a source of cobalt and potentially manganese from the shelf that surrounds Maui, Kahoolawe, Molokai, and 
Lana' $i$ islands. This sharp increase was not found for iron, and iron concentrations were somewhat higher than reported at the nearby station ALOHA.

\section{Acknowledgements}

We would like to thank the Captain and crew of the R/V Wecoma, Marc Willis, Shimi

Rii and Bob Bidigare for Chlorophyll data and supportive nutrient data, Ed Boyle for his suggestion of comparing cobalt and thorium data, and the WHOI ICP-MS facility and Dave Schneider. We thank two anonymous reviewers and editor Dennis McGillicuddy for helpful comments on this manuscript. This research was supported by NSF Grants OCE-0327225, OCE-0452883, OPP-0440840, the Office of Naval Research, the Center for Environmental Bioinorganic Chemistry at Princeton, and the Center for Microbial Oceanography and Education. 


\section{References}

Allen, C. B., Kanda, J., Laws, E. A., 1996. New production and photosynthetic rates within and outside a cyclonic mesoscale eddy in the North Pacific subtropical gyre. Deep-Sea Research I, 43: 917-936.

Benitez-Nelson, C.R., 2000. The biogeochemical cycling of phosphorus in marine systems. Earth-Science Reviews, 51: 109-135.

Benitez-Nelson, C., Bidigare, R. R., Dickey, T. D., Landry, M. R., Leonard, C. L., Brown, S. L., Nencioli, F., Rii, Y. M., Maiti, K., Becker, J. W., Bibby, T. S., Black, W., Cai, W. J., Carlson, C. A., Chen, F., Kuwahara, V. S.,Mahaffey, C., McAndrew, P. M., Quay, P. D., Rappe, M. S., Selph, K. E., Simmons, M. P., Yang, E. J., 2007. Mesoscale eddies drive increased silica export in the subtropical Pacific Ocean. Science, 316: 1017-1020.

Bidigare, R. R., Benitez-Nelson, C., Leonard, C. L., Quay, P. D., Parsons, M. L., Foley, D. G., Seki, M. P., 2003. Influence of a cyclonic eddy on microheterotroph biomass and carbon export in the lee of Hawaii. Geophysical Research Letters 30(6), 1318.

Boyle, E.A., Sclater, F., Edmond, J.M., 1976. Marine Geochemistry of Cadmium. Nature, 263 (5572): 42-44.

Boyle, E.A., Berquist, B.A., Kayser, R.A., Mahowald, N., 2005. Iron, manganese, and lead at Hawaii Ocean Time-series station ALOHA: Temporal variability and an intermediate water hydrothermal plume. Geochimica et Cosmochimica Acta, 69: 933952.

Bronk, D.A., Gilbert, P.M., Ward, B.B., 1994. Nitrogen uptake, dissolved organic nitrogen release, and new production. Science, 265: 1843-1852.

Brown, M.T., Landing, W.M., Measures, C.I., 2005. Dissolved and particulate Fe in the western and central North Pacific: Results from the 2002 IOC cruise. Geochemistry Geophysics Geosystems, 6 (10) doi:10.1029/2004GC000893.

Brown, S. L., Landry, M. R., Selph, K. E., 2007. Diatoms in the desert. Deep-Sea Research II, this volume.

Bruland, K, 1980. Oceanographic distributions of cadmium, zinc, nickel, and copper in the North Pacific. Earth and Planetary Science Letters, 47 (2): 176-198.

Bruland, K.W., Lohan, M.C. 2004. Controls of Trace Metals in Seawater. Treatise on Geochemistry Volume 6 The Oceans and Marine Geochemistry. Elderfield, H., Holland, H.D., Turekian, K.K., 6.02: 23-47.

Bruland, K.W., Rue, E.L., Smith, G.J., DiTullio, G.R., 2005. Iron, macronutrients, and diatom blooms in the Peru upwelling regime: brown and blue waters of Peru. Marine Chemistry, 93: 81-103.

Calil, P. H. R., Richards, K. J., Jia, Y., Bidigare, R. R., 2007. Eddy activity in the lee of the Hawaiian Islands. Deep-Sea Research II, this volume.

Chase, T.E., Miller, C.P., Seekins, B.A., Normark, W.B., Gutmacher, C.E., Wilde, P., Young, J.D., 1980. Topography of the Southern Hawaiian Islands. United States Geological Survey Open File Map 81-120, Plates 1-3.

Chavanne, C., Flament, P., Lumpkin, R., Dousset, B., Bentamy, A., 2002. Scatterometer observations of wind variations induced by oceanic islands: Implications for winddriven ocean circulation. Canadian Journal of Remote Sensing, 28 (3): 466-474. 
Chen, J.H., Edwards, R.L., Wasserburg, G.J., 1986. 238U, 234U and 232Th in seawater. Earth and Planetary Science Letters, 80: 241- 251.

Chen, F., Cai, W-J., Wang,Y., Rii, Y.M., Bidigare, R.R., Benitez-Nelson, C.R., 2007. Biogeochemical cycling of the carbon dioxide system and net community production estimation within a cold-core cyclonic eddy in the lee of Hawaii. Deep-Sea Research II, this volume.

Cheney, R. E., Richardson, P. L., 1976. Observed decay of a cyclonic Gulf Stream ring. Deep-Sea Research, 23 (2): 143-155.

Cullen, J., Chase, Z., Coale, K., Fitzwater, S., Sherrell, R., 2003. Effect of iron limitation on the cadmium to phosphorus ratio of natural phytoplankton assemblages from the Southern Ocean. Limnology and Oceanography, 48 (3): 1079-1087.

DeCarlo, E.H., Beltran, V.L., Tomlinson, M.S., 2004. Composition of water and suspended sediment in streams of urbanized subtropical watersheds in Hawaii. Applied Geochemistry, 19: 1011-1037.

DeCarlo, E.H., Tomlinson, M.S., Anthony, S.S., 2005. Trace elements in streambed sediments of small subtropical streams on O'ahu, Hawai'i: Results from the USGS NAWQA program. Applied Geochemistry, 20: 2157-2188.

Dickey, T. D., Nencioli, F., Kuwahara, V. S., Leonard, C. L., Black, W., Bidigare, R. R., Rii, Y. M., Zhang, Q., 2007. Physical and bio-optical observations of oceanic cyclones west of the island of Hawai'i. Deep-Sea Research II, this volume.

Eakins, B.W., Robinson, J.E., Kanamatsu, T., Naka, J., Smith, J.R., Takahashi, E., Clague, D.A., 2003. Hawaii's Volcanoes Revealed. United States Geological Survey Geologic Investigations Series I-2809.

Edmond, J.M., Measures, C., McDuff, R.E., Chan, L.H., Collier, R., Grant, B., Gordon, L.I., Corliss, J.B., 1979. Ridge crest hydrothermal activity and the balances of the major and minor elements in the ocean: The Galapagos data. Earth and Planetary Science Letters, 46: 1-18.

Ellwood, M.J., Hunter, K.A., 1999. Determination of the Zn/Si ratio in diatom opal: A method for the separation, cleaning and dissolution of diatoms. Mar. Chem. 66. 149160.

Emerson, S., Kalhorn, S., Jacobs, L., Tebo, B.M., Nealson, K.H., Rosson., R.A., 1982. Environmental oxidation rate of manganese(II): bacterial catalysis. Geochimica et Cosmochima Acta, 46 (6): 1073-1079.

Falkowski, P. G., Ziemann, D., Kolber, Z., Bienfang, P. K., 1991. Role of eddy pumping in enhancing primary production in the ocean. Nature, 352: 55-58.

Fischer, A. S.,Weller, R. A., Rudnick, D. L., Eriksen, C. C., Lee, C. M., Brink, K. H., Fox, C. A., Leben, R. R., 2002. Mesoscale eddies, coastal upwelling, and the upperocean heat budget in the Arabian Sea. Deep-Sea Research II, 49 (12): 2231-2264.

Fitzwater, S.E., Coale, K.H., Gordon, M.R., Johnson, K.S., Ondrusek, M.E., 1996. Iron deficiency and phytoplankton growth in the equatorial Pacific. Deep-Sea Research II, 43 (4-6): 995-1015.

Garcia, M.O., Kurz, M.D., Muenow, D.W., 1990. Mahukona: The missing Hawaiian volcano. Geology, 18: 1111-1114.

Gordon, R.M., Johnson, K.S., Coale, K.H., 1998. The behaviour of iron and other trace elements during the IronEx-I and PlumEx experiments in the Equatorial Pacific. Deep-Sea Research II, 45: 995-1041. 
Herrera-Melian, J., Hernandez-Brito, J., Gelado-Caballero, M. and Perez-Pena, J., 1994. Direct determination of cobalt in unpurged oceanic seawater by high speed adsorptive cathodic stripping voltammetry. Analytica Chimica Acta, 299: 59-67.

Johnson, K.S., Stout, P.M., Berelson, W.M., Sakamoto-Arnold, C.M, 1988. Cobalt and copper distributions in the waters of Santa Monica Basin, California. Nature, 332: $527-530$.

Johnson, K.S., Coale, K.H., Berelson, W.M., Gordon, R.M., 1996. On the formation of the manganese maximum in the oxygen minimum. Geochimica et Cosmochimica Acta, 60 (8): 1291-1299.

Johnson, K.S., Gordon, R.M., Coale, K.H., 1997. What controls dissolved iron concentrations in the world ocean? Marine Chemistry, 57: 137-161.

Johnson, K.S., Elrod, V.A., Fitzwater, S.E., Plant, J.N., Chavez, F.P., Tanner, S.J., Gordon, R.M., Westphal, D.L., Perry, K.D., Wu, J., Karl, D.M., 2003. Surface oceanlower atmosphere interactions in the Northeast Pacific Ocean gyre: Aerosols, iron and the ecosystem response. Global Biogeochemical Cycles, 17: doi:10.1029/2002GB002004.

Johnson, W.K., Miller, L.A., Sutherland, N.E., Wong, C.S., 2005. Iron transport by mesoscale Haida eddies in the Gulf of Alaska. Deep-Sea Research II, 52: 933-953.

Johnson, K.S., Boyle, E., Bruland, K., Coale, K., Measures, C., Moffett, J., Aguilar-Islas, A., Barbeau, K., Bergquist, B., Bowie, A., Buck, K., Cai, Y., Chase, Z., Cullen, J., Doi, T., Elrod, V., Fitzwater, S., Gordon, M. King, A. Laan, P., Laglera-Baquer, P., Landing, W., Lohan, M., Mendez, J., Milne, A., Obata, H., Ossiander, L., Plant, J., Sarthou, G., Sedwick, P., Smith, G.J., Sohst, B., Tanner, S., van den Berg, S., Wu, J., 2007. Developing Standards for Dissolved Iron in Seawater. EOS. 88:11. 131-132.

Karl, D.M., Yanagi, K., 1997. Partial Characterization of the Dissolved Organic Phosphorus Pool in the Oligotrophic North Pacific Ocean. Limnology and Oceanography, 42 (6): 1398-1405.

Lumpkin, C. F., 1998. Eddies and currents in the Hawaii islands. Ph.D. thesis, University of Hawaii.

Martin, J.H., Knauer, G.A., Broenkow, W.W., 1985. VERTEX: the lateral transport of $\mathrm{Mn}$ in the northeast Pacific. Deep-Sea Research I, 32 (11): 1405-1427.

Martin, J.H., Gordon, R.M., Fitzwater, S., Broenkow, W.W., 1989. VERTEX: phytoplankton/iron studies in the Gulf of Alaska. Deep-Sea Research I, 36 (5): 649680.

Martin, J.H., Gordon, R.M., Fitzwater, S.E., 1991. The Case for Iron. Limnology and Oceanography, 36 (8): 1793-1802.

Maiti, K., Benitez-Nelson, C.R., Rii, Y.M., Bidigare, R.R., 2007. The Influence of a Mature Cyclonic Eddy on Particle Export, Deep-Sea Research II, this volume.

McGillicuddy, D.J., Robinson, A.R., Siegel, D.A., Jannasch, H.W., Johnson, R., Dickey, T.D., McNeil, J., Michaels, A.F., Knap, A.H., 1998. Influence of mesoscale eddies on new production in the Sargasso Sea. Nature, 394: 263-266.

McGillicuddy, D.J., Anderson, L.A., Bates, N.R., Bibby, T., Buesseler, K.O., Carlson, C.A., Davis, C.S., Ewart, C., Falkowski, P.G., Goldthwait, S.A., Hansell, D.A., Jenkins, W.J., Johnson, R., Kosnyrev, V.K., Ledwell, J.R., Li, Q.P., Siegel, D.A., Steinberg, D.K., 2007. Eddy/Wind Interactions Stimulate Extraordinary Mid-Ocean Plankton Blooms. Science, 316: 1021-1026. 
Moffett, J.W., Ho, J., 1996. Oxidation of cobalt and manganese in seawater via a common microbially catalyzed pathway. Geochimica et Cosmochimica Acta, 60 (18): 3415-3424.

Morel, F.M.M., Milligan, A.J., Saito, M.A., 2003. Marine Bioinorganic Chemistry: The Role of Trace Metals in the Oceanic Cycles of Major Nutrients. Treatise on Geochemistry Volume 6, The Oceans and Marine Geochemistry. Elderfield, H., Holland, H.D., Turekian, K.K., 6.05: 113-143.

Moore, J.G., Clague, D.A., 2004. Hawaiian submarine manganese-iron oxide crusts - A dating tool? GSA Bulletin, 116: 337-347.

Nencioli, F., Kuwahara, V. S., Dickey, T. D., Rii, Y. M., Bidigare, R. R., 2007. Physical dynamics and biological implications of a mesoscale eddy in the lee of Hawai'i: Cyclone Opal observations during E-Flux III. Deep-Sea Research II, this volume.

Olaizola, M., Ziemann, D.A., Bienfang, P.K., Walsh, W.A., Conquest, L.D., 1993. Eddyinduced oscillations of the pycnocline affect the floristic composition and depth distribution of phytoplankton in the subtropical Pacific. Marine Biology, 116: 533542.

Oschlies, A., Garcon, V., 1998. Eddy-induced enhancement of primary production in a model of the North Atlantic Ocean. Nature, 394: 266-269.

Parrington, J.R., Zoller, W.H., Aras, N.K., 1983. Asian dust: Seasonal transport to the Hawaiian Islands. Science, 220: 195-198.

Perry, K.D., Cahill, T.A., Schnell, R.C., Harris, J.M., 1999. Long-range transport of anthropogenic aerosols to the National Oceanic and Atmospheric Administration baseline station at Mauna Loa Observatory, Hawaii. Journal of Geophysical Research, 104: 18521-18533.

Patzert, W. C., 1969. Eddies in Hawaiian Islands. Tech. Rep. HIG-69-8, Hawaii Institute of Geophysics, University of Hawaii.

Peterson, T.D., Frank, A.W., Harrison, P.J., 2005. Macronutrient dynamics in an anticyclonic mesoscale eddy in the Gulf of Alaska. Deep-Sea Research II, 52: 909932.

Pike, S.M., Buesseler, K.O., Andrews, J.A., Savoye, N., 2005. Quantification of ${ }^{234} \mathrm{Th}$ recovery in small volume sea water samples by inductively coupled plasma mass spectrometry. Journal of Radioanalytical and Nuclear Chemistry, 263(2): 355-360

Redfield, S.C., 1958. The biological control of chemical factors in the environment. American Scientist, 46: 205-222.

Rii, Y. M., Brown, S. L., Nencioli, F., Kuwahara, V. S., Dickey, T. D., Karl, D. M., Bidigare, R. R., 2007. The transient oasis: nutrient-phytoplankton dynamics and particle export in Hawaiian lee cyclones. Deep-Sea Research II, this volume.

Rutgers van der Loeff, M.R., Sarin, M.M., Baskaran, M., Benitez-Nelson, C., Buesseler, K.O., Charette, M., Dai, M., Gustafsson, O., Masque, P., Morris, P.J., 2006. A review of present techniques and methodological advances in analyzing ${ }^{234} \mathrm{Th}$ in aquatic systems. Marine Chemistry, 100 (3-4): 190-212.

Saito, M.A., Moffett, J.W., 2001. Complexation of cobalt by natural organic ligands in the Sargasso Sea as determined by a new high-sensitivity electrochemical cobalt speciation method suitable for open ocean work. Marine Chemistry, 75: 49-68.

Saito, M.A., Moffett, J.W., 2002. Temporal and spatial variability of cobalt in the Atlantic Ocean. Geochimica et Cosmochimica Acta, 66: 1943-1953. 
Saito, M.A., Moffett, J.W., Chisholm, S.W., Waterbury, J.B., 2002. Cobalt limitation and uptake in Prochlorococcus. Limnology and Oceanography, 47(6): 1629-1636.

Saito, M.A., Moffett, J.W., DiTullio, G.R., 2004. Cobalt and nickel in the Peru upwelling region: A major flux of labile cobalt utilized as a micronutrient. Global Biogeochemical Cycles, 18: dio:10.1029/2003GB002216.

Saito, M.A., Rocap, G., Moffett, J.W., 2005. Production of cobalt binding ligands in a Synechococcus feature at the Costa Rica upwelling dome. Limnology and Oceanography, 50 (1): 279-290.

Saito, M.A., Schneider, D.L., 2006. Examination of precipitation chemistry and improvements in precision using the $\mathrm{Mg}(\mathrm{OH})_{2}$ preconcentration inductively coupled plasma mass spectrometry (ICP-MS) methods for high-throughput analysis of openocean Fe and Mn in seawater. Analytica Chimica Acta, 565: 222-233.

Sakamoto, C., Yuji, O., Kanazawa, K., Ayano, E., Nishimura, T., Ando, M., Kikuchi, A., Okano, T., 2004. Temperature- and pH-responsive aminopropyl-silica ion-exchange columns grafted with copolymers of $\mathrm{N}$-isopropylacrylamide. Journal of Chromatography A, 1030: 247-253.

Sedwick, P.N., McMurty, G.M., Macdougall, J.D., 1992. Chemistry of hydrothermal solutions from Pele's Vents, Loihi Seamount, Hawaii. Geochimica et Cosmochimica Acta, 56: 3643-3667.

Sedwick, P.N., Church, T.M., Bowie, A.R., Marsay, C.M., Ussher, S.J., Achilles, K.M., Lethaby, P.J., Johnson, R.J., Sarin, M.M, McGillicuddy, D.J., 2005. Iron in the Sargasso Sea (Bermuda Atlantic Time-series Study region) during summer: Eolian imprint, spatiotemporal variability, and ecological implications. Global Biogeochemical Cycles, 19: doi: 10.1029/2004GB002445.

Seki, M. P., Polovina, J. J., Brainard, R. E., Bidigare, R. R., Leonard, C. L., Foley, D. G., 2001. Biological enhancement at cyclonic eddies tracked with GOES thermal imagery in Hawaiian waters. Geophysical Research Letters, 28 (8): 1583-1586.

Seki, M.P., Lumpkin R, Flament, P., 2002. Hawaii cyclonic eddies and blue marlin catches: The case study of the 1995 Hawaiian International Billfish Tournament. Journal of Oceanography, 58 (5): 739-745.

Sherrell, R.M., Boyle, E.A., 1992. The trace metal composition of suspended particles in the oceanic water column near Bermuda. Earth and Planetary Science Letters, 111: 155-174.

Strzepek, R.F., Maldonado, M.T., Higgins, J.L, Hall, J., Safi, K, Wilhelm, S.W., Boyd, P.W., 2005. Spinning the "Ferrous Wheel": The importance of the microbial community in an iron budget during the FeCycle experiment. Global Biogeochemical Cycles, 19 (4): doi:10.1029/2005GB002490.

Sunda, W.G., Huntsman, S.A., 1985. Regulation of cellular manganese and manganese transport rates in the unicellular alga Chlamydomonas. Limnology and Oceanography, 30: 71-80.

Sunda, W.G., Huntsman, S.A., 1988. Effect of sunlight on redox cycles of manganese in the southwestern Sargasso Sea. Deep-Sea Research, 35: 1297-1317.

Sunda, W.G., Huntsman, S.A., 1995. Cobalt and Zinc Interreplacement in Marine Phytoplankton: Biological and Geochemical Implications. Limnology and Oceanography, 40 (8): 1404-1417. 
Taylor, S.R., McLennan, S.M., 1985. The Continental Crust: Its Composition and Evolution. Blackwell Scientific Publications.

Tebo, B., Nealson, K., Emerson, S., Jacobs, L., 1984. Microbial mediation of Mn(II) and $\mathrm{Co}(\mathrm{II})$ precipitation at the $\mathrm{O}_{2} / \mathrm{H}_{2}$ interfaces in two anoxic fjords. Limnology and Oceanography, 29: 1247-1258.

Thamdrup, B., Glud, R.N., Hansen, J.W., 1994. Manganese oxidation and in situ manganese fluxes from a coastal sediment. Geochimica et Cosmochimica Acta, 58 (11): 2563-2570.

Tyrell, T., 1999. The relative influence of nitrogen relative to phosphorus on oceanic primary production. Nature, 400: 525-531.

Vaillancourt, R. D., J, M., Seki, M. P., Parsons, M. L., Bidigare, R. R., 2003. Impact of a cyclonic eddy on phytoplankton community structure and photosynthetic competency in the subtropical North Pacific Ocean. Deep-Sea Research I, 50: 829-847.

Vega, Marisol and van den Berg, Constant M.G., 1997. Determination of Cobalt in Seawater by Catalytic Adsorptive Cathodic Stripping Voltammetry. Analytical Chemistry, 69: 874-881.

Wheat, C.G., Jannasch, H.W., Plant, J.N., Moyer, C.L., Sansone, F.J., McMurty, G.M., 2000. Continuous sampling of hydrothermal fluids from Loihi Seamount after the 1996 event. Journal of Geophysical Research, 105 (B8): 19,353-19,367.

Wong, G.T., Pai, S., Chung, S., 1995. Cobalt in the Western Philippine Sea. Oceanologica Acta, 18 (6): 631-638.

$\mathrm{Wu}$, J. and Luther, G.W., 1995. Complexation of Fe(III) by natural organic ligands in the Northwest Atlantic Ocean by a competitive ligand equilibration method and a kinetic approach. Marine Chemistry, 50: 159-177. 


\section{Figure Captions}

Figure 1. a) Sampling area for E-Flux II in January, 2005 and E-Flux III in March, 2005. b) Bathymetry around the Hawaiian Islands. There is a prominent shelf at $\sim 500 \mathrm{~m}$ surrounding the islands in proximity to the study site (modified from USGS, Eakins et al. 2003).

Figure 2. a) Sample overlay for E-Flux II total dissolved cobalt data. Closed circles represent the vast majority of samples analyzed, while the open circles represent high cobalt concentrations outside the generally observed trend. These points are denoted in Table 1 with an asterisk. With these high-throughput analyses, occasional samples were measured that were not oceanographically consistent with the bulk of the data. Note the depletion of total dissolved cobalt in the surface waters as a result of biological uptake. b) E-Flux II Transect 6 (see Figure 1a) contour plot showing cobalt concentration trends with depth (tdCo denotes "total dissolved cobalt"). The data from which the contour plot was made are overlain as black squares.

Figure 3. Vertical profiles for dissolved manganese, iron, cobalt, and phosphate and hydrographic data for Station 81 from E-Flux II. High concentrations of cobalt are present at 400 to $600 \mathrm{~m}$ in all stations and suggest an intermediate depth source for cobalt. Phosphate data from the CTD bottle cast are plotted with Go-Flo rosette cast data to confirm sampling accuracy. Labile cobalt is defined as the fraction of the total dissolved cobalt that is not bound by strong organic ligands (Saito and Moffett 2004).

Figure 4. Surface total cobalt profiles for E-Flux III from inside Cyclone Opal (In stations) and outside (Out station). Shallow cobalt maxima are observed in two profiles within Cyclone Opal, but not in surrounding waters. These maxima occur at the same depth that the ${ }^{234} \mathrm{Th}$ disequilibria ends ( $100 \mathrm{~m}$ see Figure 5$)$, suggesting that these shallow cobalt maxima are related to export by particle flux and subsequent shallow remineralization. Averaged nitrate + nitrite $(\mathrm{N}+\mathrm{N})$ values from In and Out stations $(\mathrm{n}=3$ and $n=5$, respectively) in E-Flux III also show a slight bulge between $\sim 75-100 \mathrm{~m}$ and an 
increase in upper column $\mathrm{N}+\mathrm{N}$ inventory, likely due to a combination of the shoaling isopycnals and a remineralization signal (Data from Nencioli et al. this volume).

Figure 5. Contour plot of the ${ }^{234} \mathrm{Th} /{ }^{238} \mathrm{U}$ ratio for the $6 \mathrm{IN}$ stations at the center of E-Flux III Cyclone Opal. ${ }^{234} \mathrm{Th} /{ }^{238} \mathrm{U}$ ratio equal to 1 represents that both the daughter $\left({ }^{234} \mathrm{Th}\right)$ and the parent $\left({ }^{238} \mathrm{U}\right)$ isotope is in equilibrium. ${ }^{234} \mathrm{Th} /{ }^{238} \mathrm{U}$ ratio of less than 1 represents particle scavenging where as ${ }^{234} \mathrm{Th} /{ }^{238} \mathrm{U}$ ratio greater than 1 represents particle remineralisation. A remineralization feature is clearly observed at $\sim 100 \mathrm{~m}$ depth, coinciding with the peak observed in cobalt at this depth (see Figure 4). Adapted from Maiti et al. this volume.

Figure 6. A proposed cobalt concentrating mechanism within Cyclone Opal, where the cobalt is concentrated by a succession of events: upwelling, biological utilization, and subsequent export associated with POC, shallow and significant remineralization of cobalt from organic matter, and upwelling again.

Figure 7. Co:P correlation from E-Flux II and III surface waters. There is a strong correlation between Co and P during E-Flux III $\left(\mathrm{r}^{2}=0.91\right)$ with a slope of $37 \mu \mathrm{mol} \mathrm{Co}$ $\mathrm{mol}^{-1} \mathrm{P}$, and a weaker correlation during E-Flux II. A slope of $29 \mu \mathrm{mol} \mathrm{Co} \mathrm{mol}{ }^{-1} \mathrm{P}$ $\left(r^{2}=0.63\right)$ was calculated from the aggregate of all profiles for E-Flux II that had enough data points $(\geq 4)$ to identify oceanographically consistent features and did not have concentrations identified as outside the generally observed trend for the upper water column (refer to Figure 2a). These points are plotted with open circles and labeled "others."

Figure 8. Chlorophyll $a$ data for select E-Flux II and III In and Out stations. There is a noticeable increase in Chlorophyll $a$ concentration at the E-Flux III In stations in comparison to E-Flux II and the Out stations in E-Flux III.

Figure 9. Schematic of the various processes influencing the Co:P correlation in Hybridtype metal-phosphate (HTM) space. a) The HTM:P line represents the aggregate 
biological cellular quotas for the hybrid-type trace metal and P. Remineralization and biological uptake should change the placement of a given sample along that line, but not deviating from it. Deviation from this line is caused by processes affecting the metal concentration but not phosphate concentrations. Examples include biotic and abiotic scavenging (where biotic scavenging refers to co-oxidation by manganese oxidizers and is distinct from biological utilization as a micronutrient), aeolian deposition, or release from sediments. The process of "uptake by biota / entrainment" should manipulate both the hybrid-trace metal and phosphate simultaneously, first through biological uptake then through remineralization of particulate organic matter. Each phytoplankton species within the natural phytoplankton assemblage likely has a unique macronutrient and micronutrient cellular stoichiometry based on the specific environmental concentrations of those nutrients (e.g. Sunda and Huntsman 1995). Thus each arrow in the "uptake by biota / entrainment" group represents a potential species and its stoichiometry, and the summation of these species create the aggregate community ratio of HTM:P. Upwelling will affect both elements, however due to the depletion of HTM in intermediate waters by scavenging, the ratio of HTM:P in upwelled waters will be lower than in surface waters, with the range of arrows representing variability in the extent of HTM scavenging. b) Variations in aggregate biological cellular quotas for the hybrid-type trace metal and $\mathrm{P}$ can influence the slope significantly. A range of $\mathrm{Co}: \mathrm{P}$ correlations that have been observed previously are shown $\left(\mathrm{Q}_{\mathrm{Co}}=248 \mu \mathrm{mol} \mathrm{Co} \mathrm{mol}^{-1} \mathrm{C}\right.$ from Saito et al. 2004, $\mathrm{Q}_{\mathrm{Co}}=$ $36 \mu \mathrm{mol} \mathrm{Co} \mathrm{mol}{ }^{-1} \mathrm{C}$ from Martin et al. 1989). Factors that could affect $\mathrm{Q}_{\mathrm{Co}}$ include biological community composition, community shift, biochemical substitution of zinc for cobalt in eukaryotic phytoplankton, and changes in the bioavailability of cobalt.

Figure 10. Vertical profiles for total dissolvable manganese, total cobalt, phosphate, and hydrographic data for select stations in E-Flux III. Note that phosphate data were unavailable for In 1. Phosphate data for In 2 were less than one nautical mile from In 1, and are presented in place of In 1. High concentrations of cobalt are present at 400 to $600 \mathrm{~m}$ in all stations. The peaks at 400 to $600 \mathrm{~m}$ suggest that there is an intermediate depth source for influx of Co. The peaks are supported by replicates analyses, and by the supporting adjacent points in the profile. 


\section{Table 1. Collected data from E-Flux II and III}

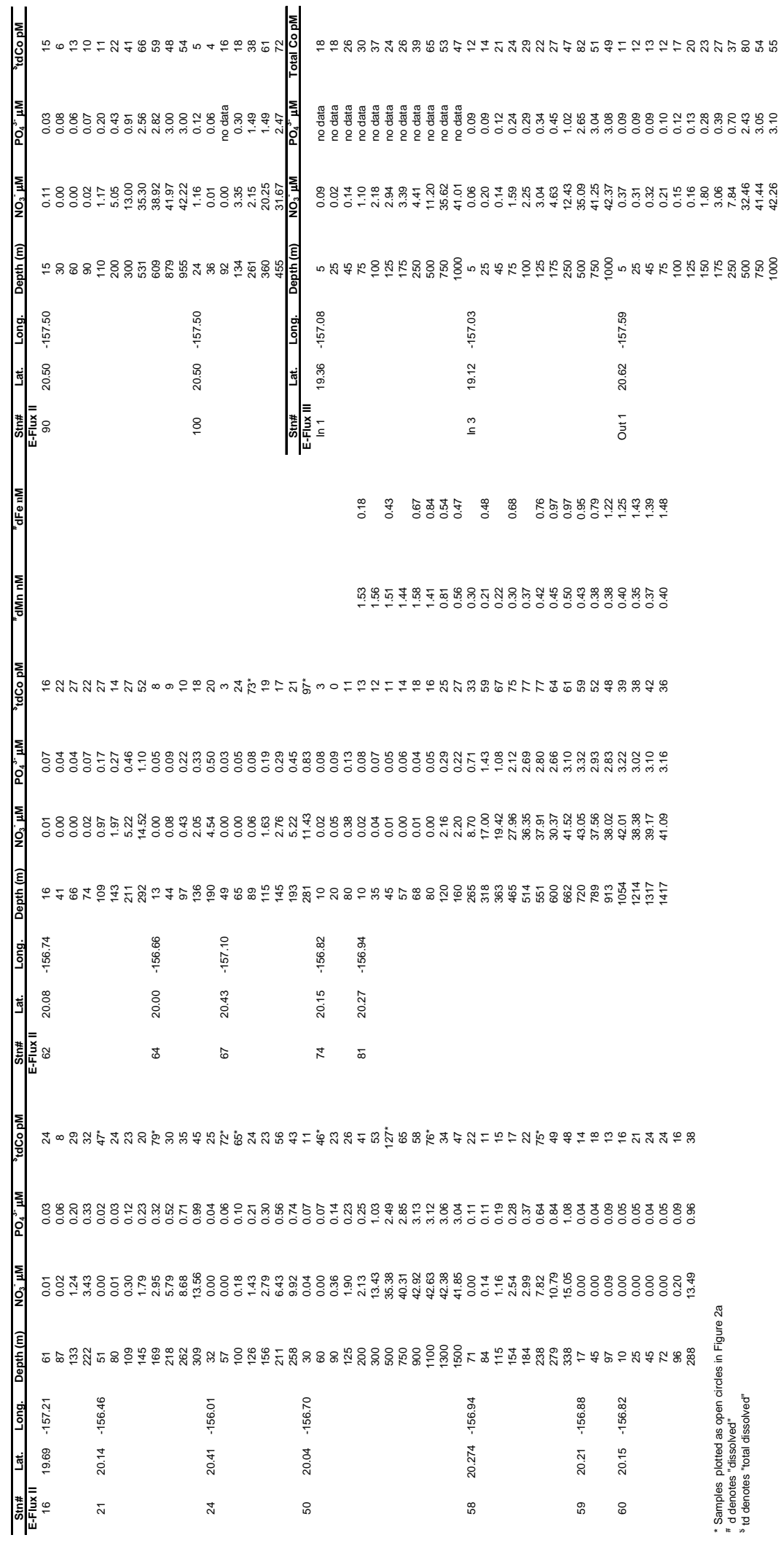


Table 2. Inventories in the upper $100 \mathrm{~m}$

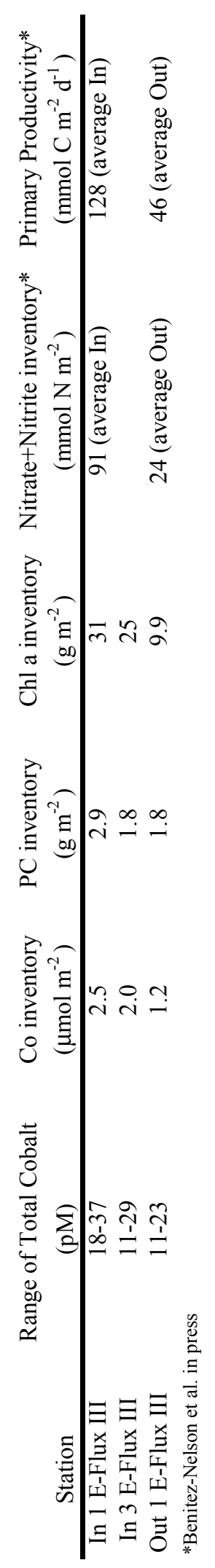


Figure 1.
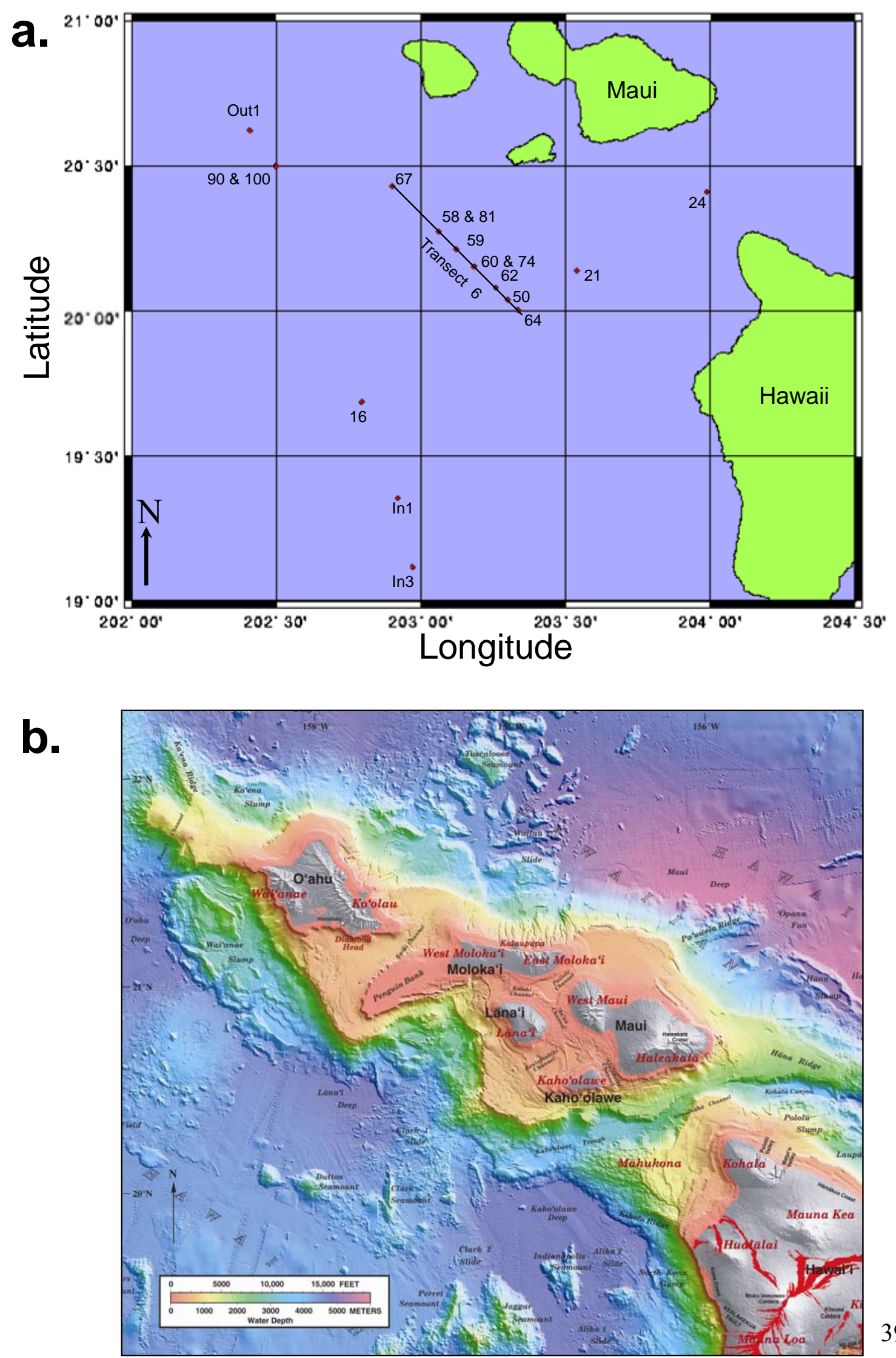
Figure 2.

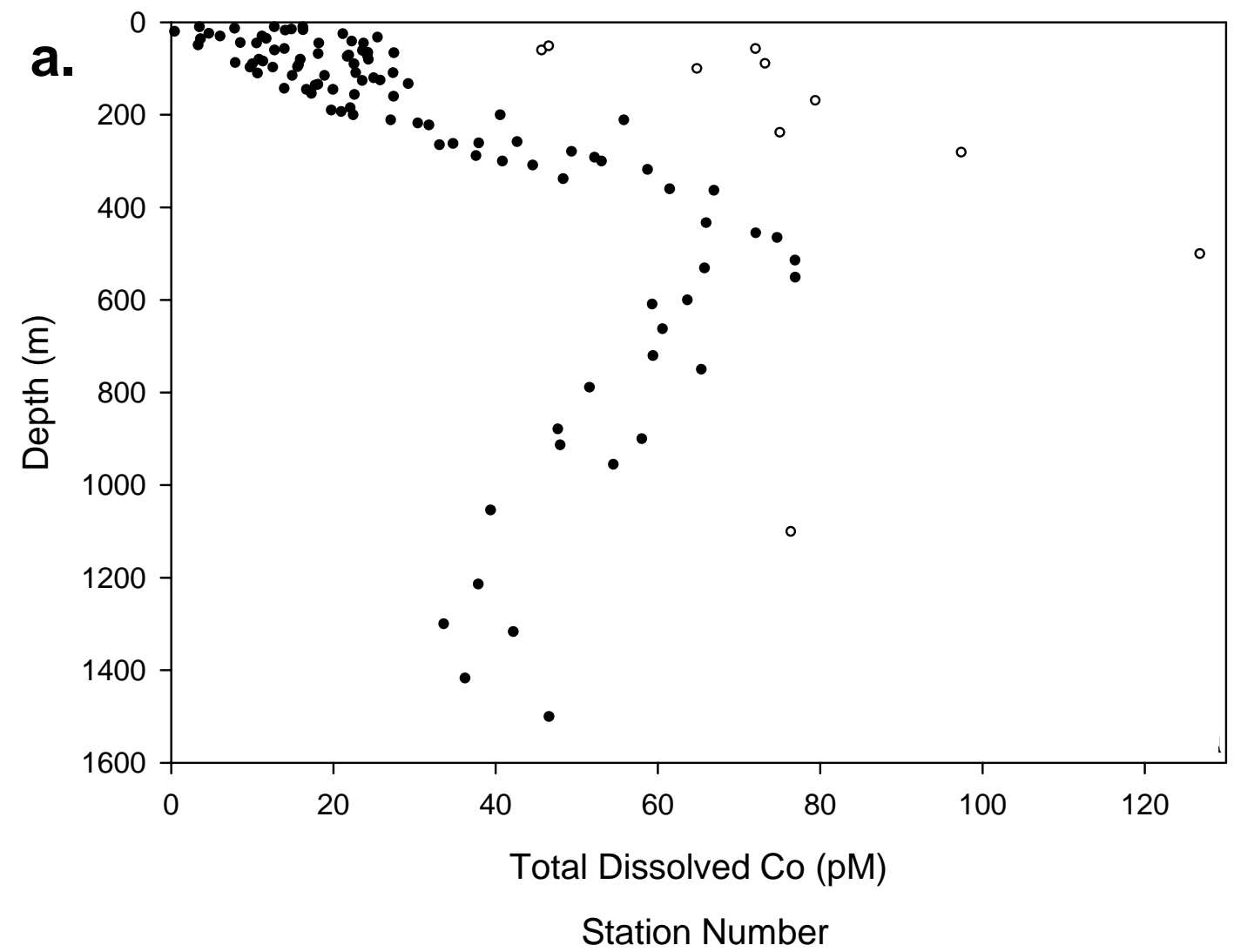

b.

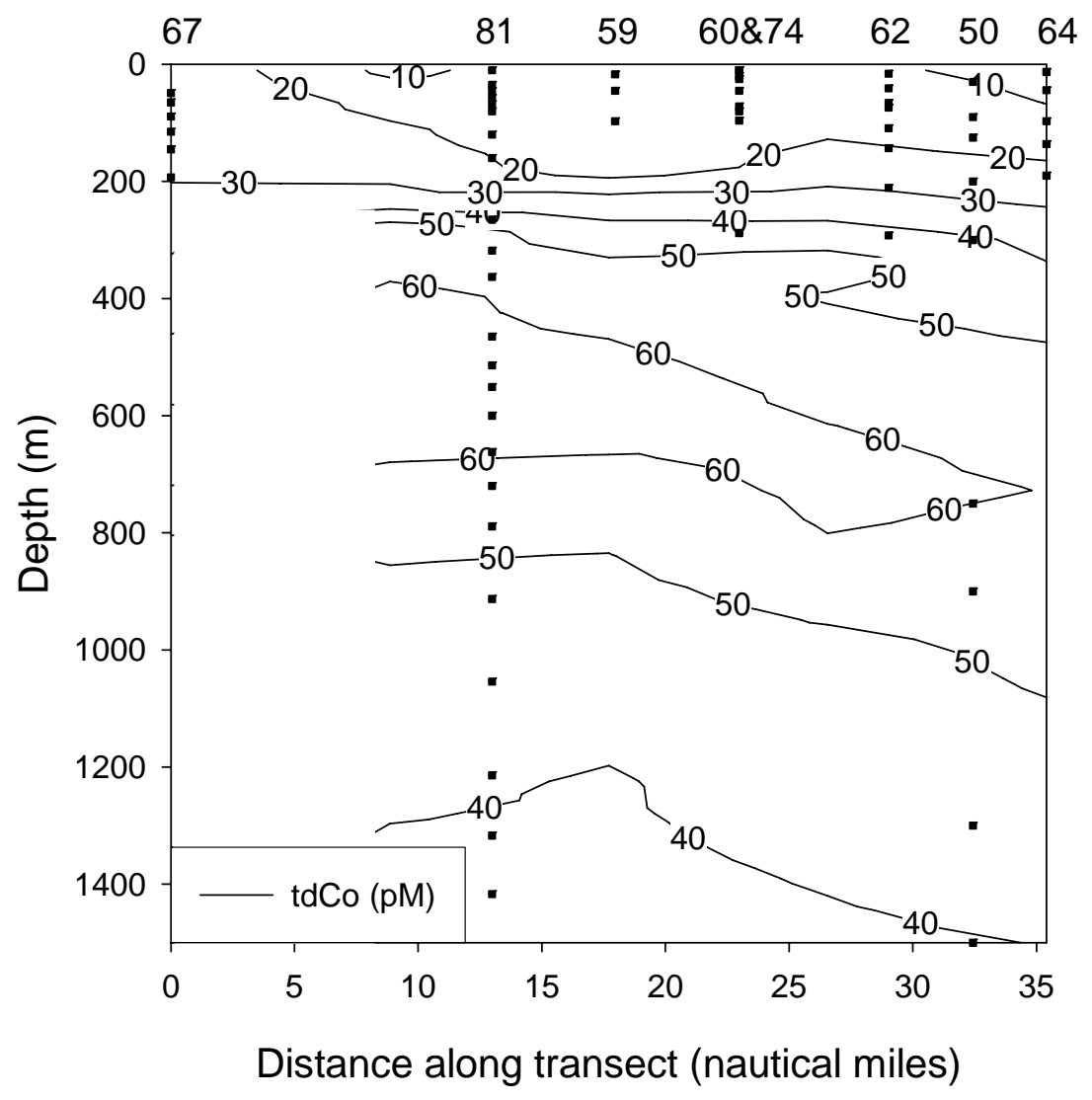


Figure 3.

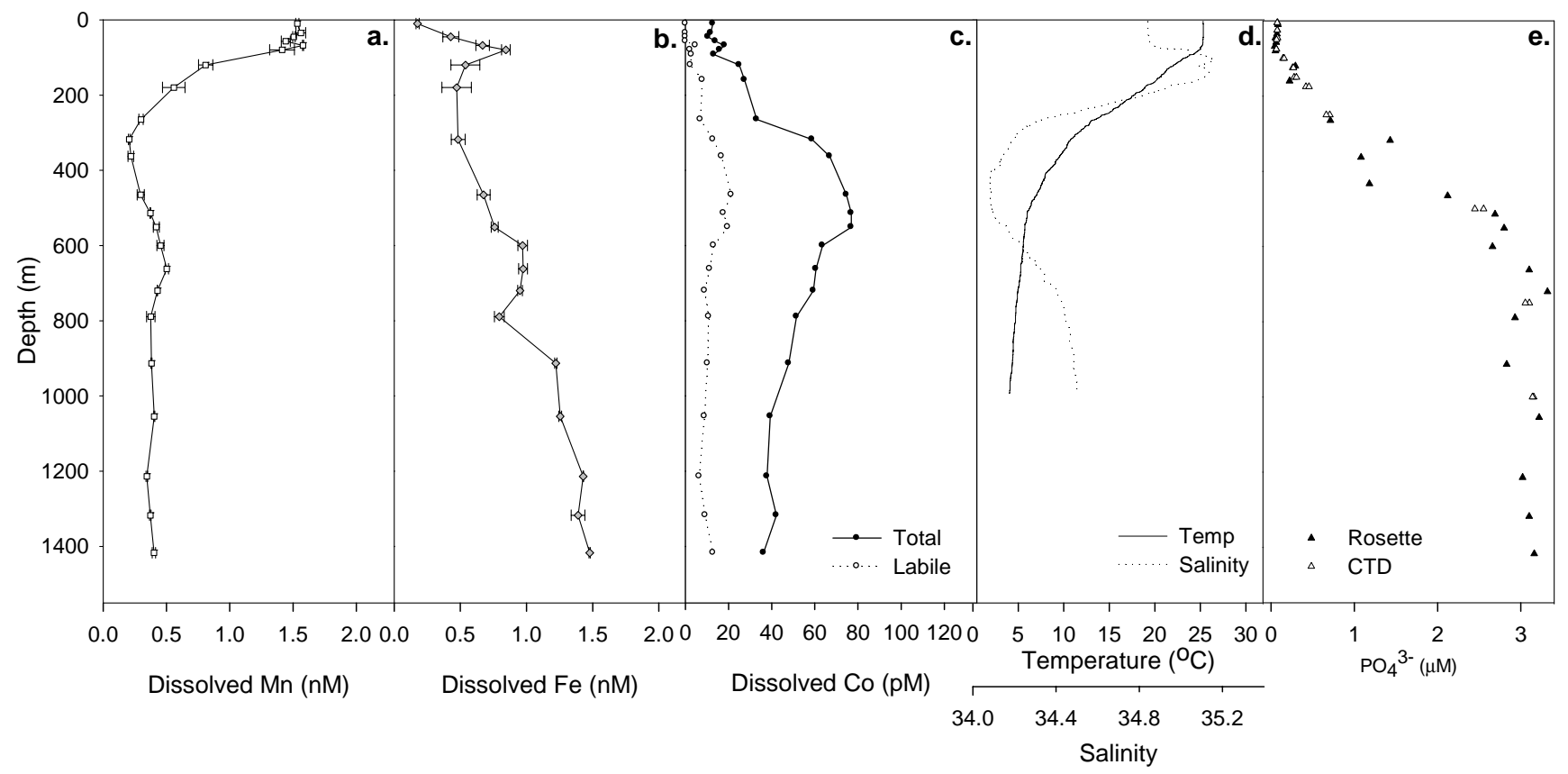


Figure 4.

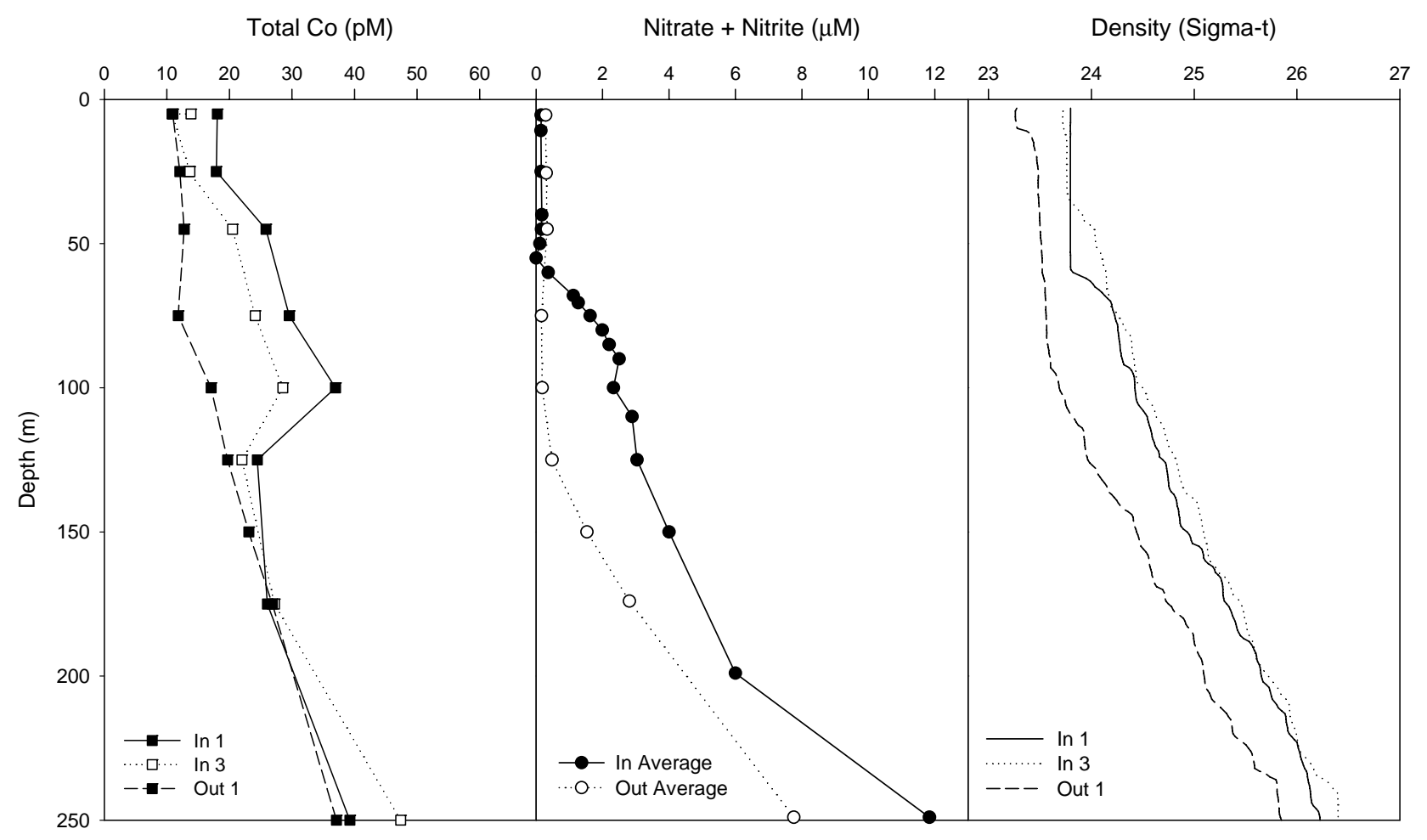


Figure 5.

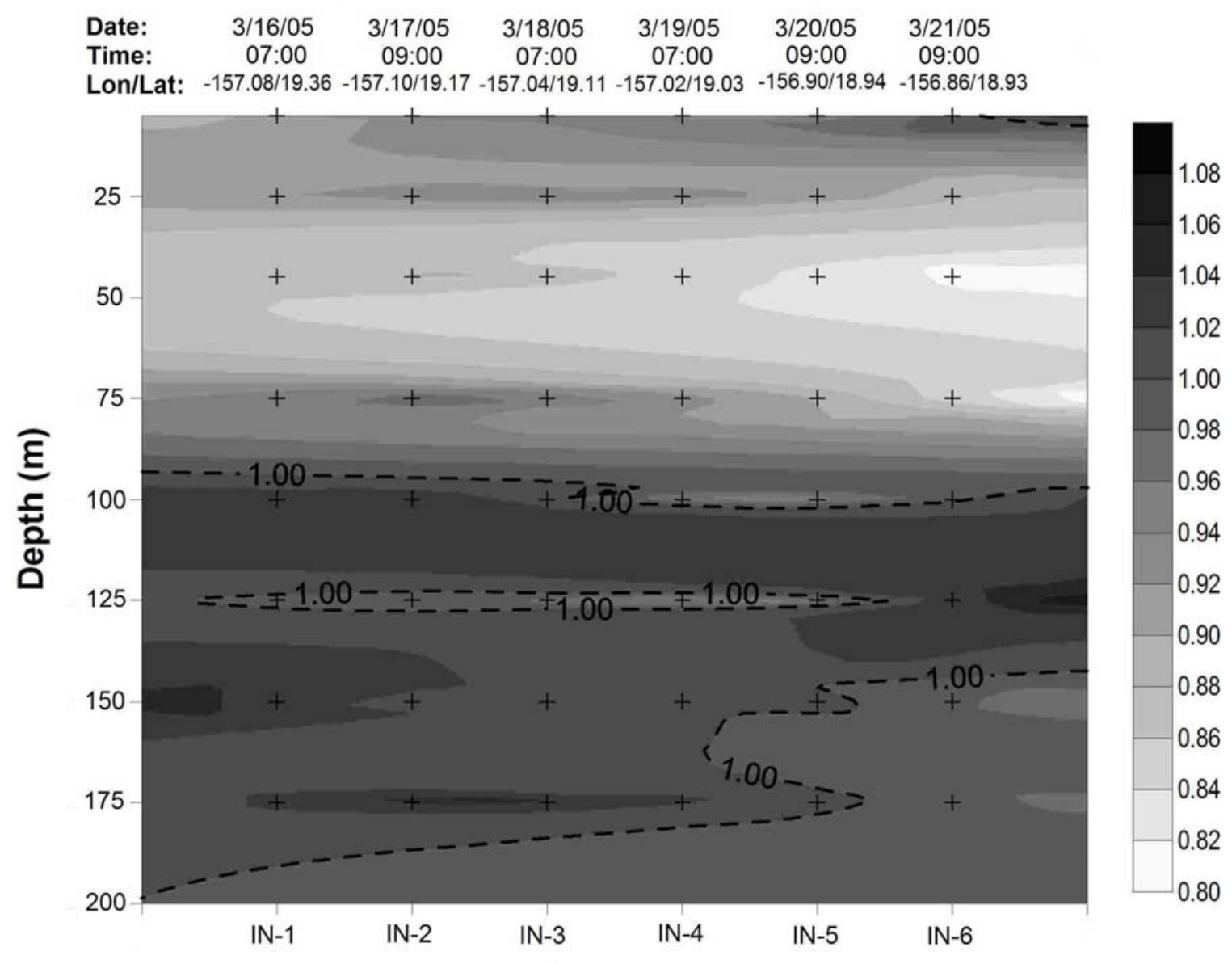

Stations 
Figure 6.

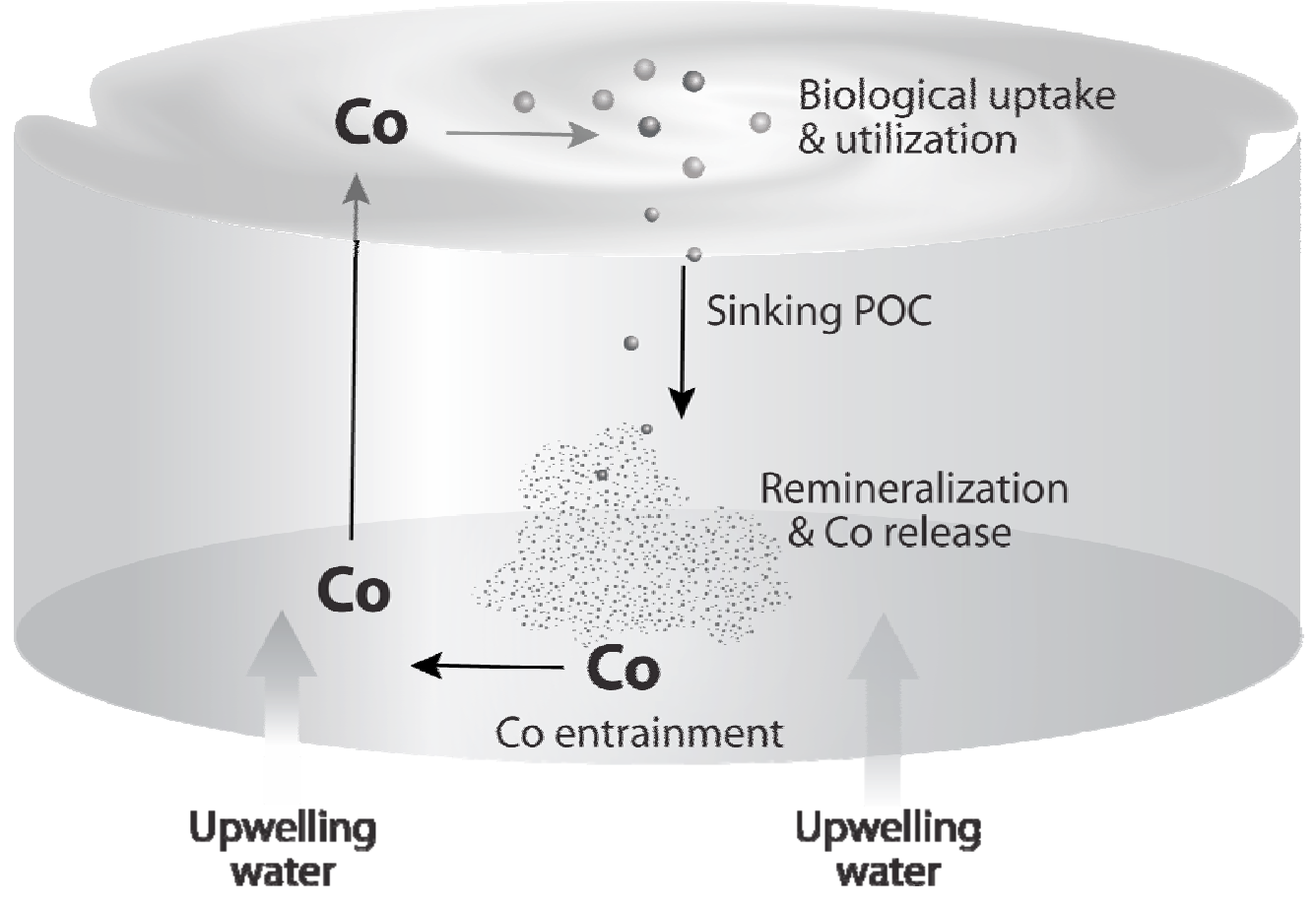


Figure 7.
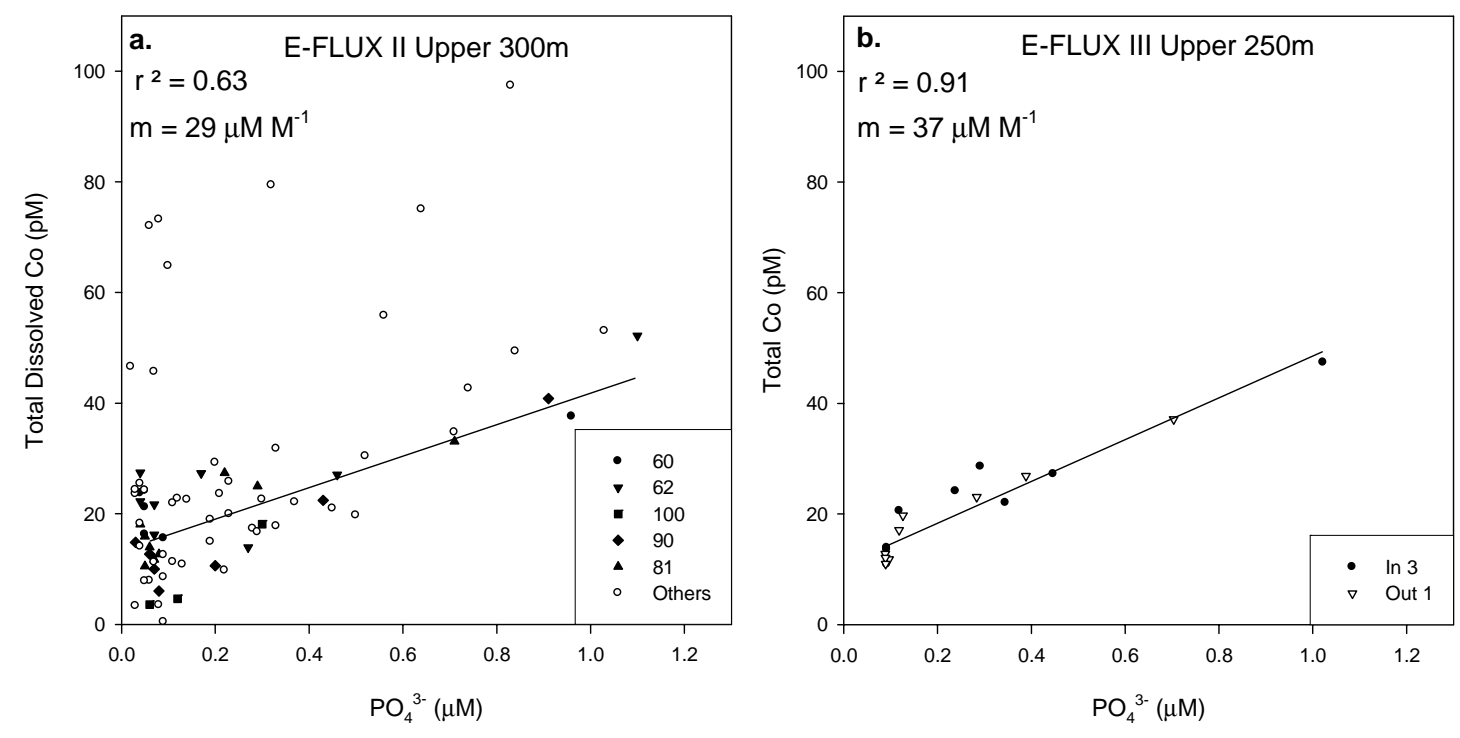
Figure 8.

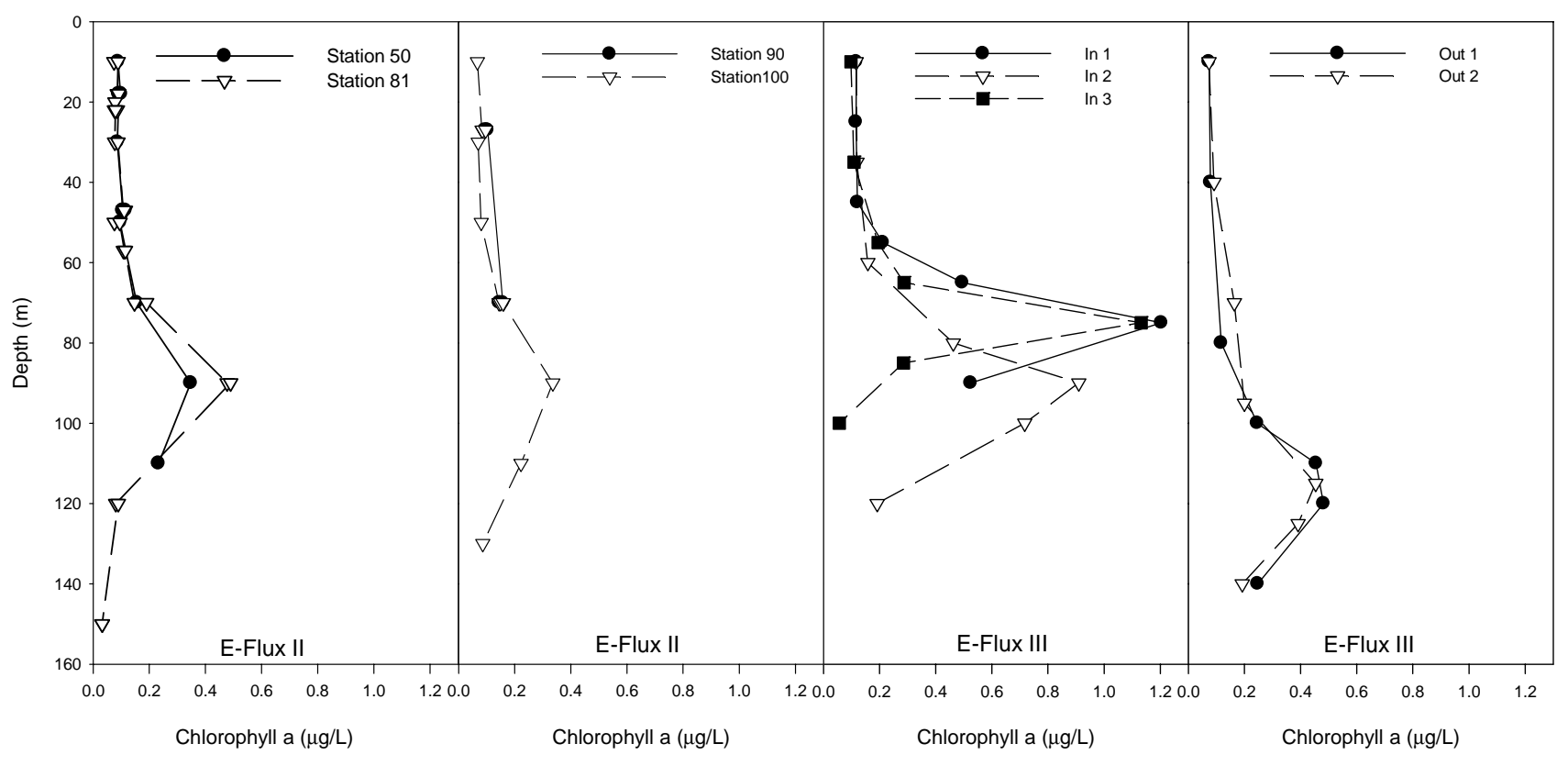


Figure 9.
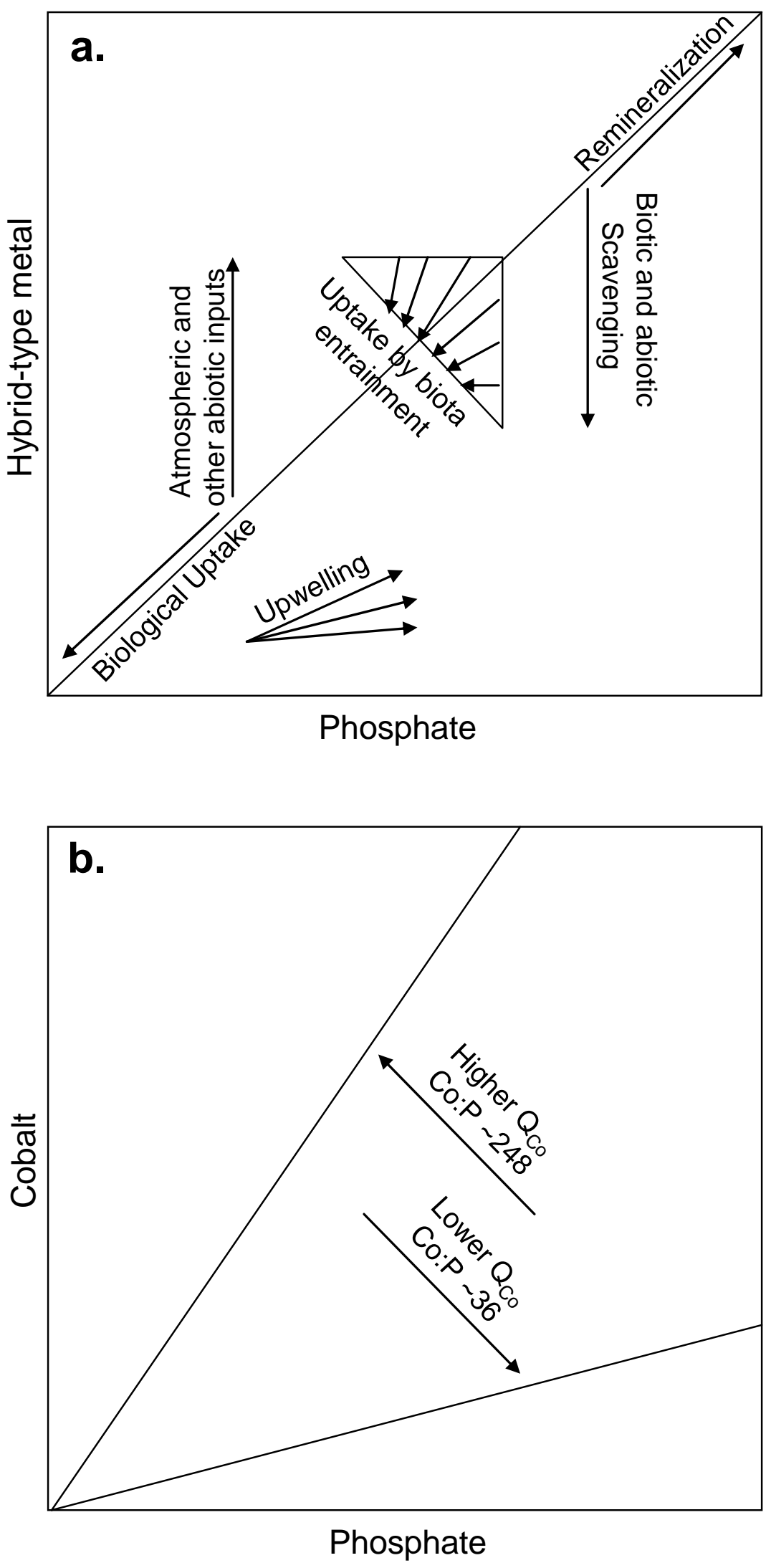
Figure 10.

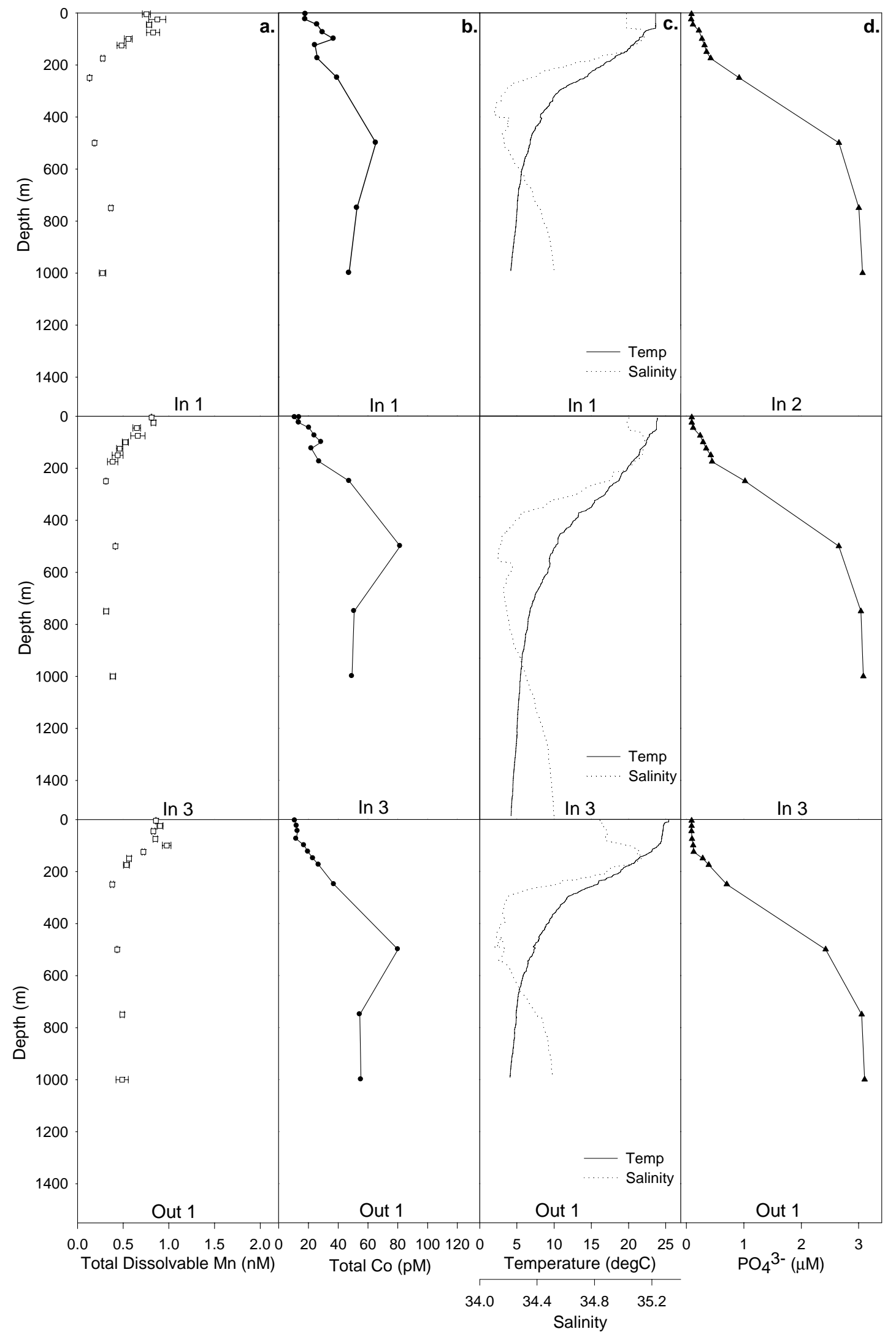

